\title{
TURISMO Y ESPACIOS NATURALES PROTEGIDOS EN COSTA RICA: ENFRENTAMIENTO O CONCERTACIÓN
}

\section{TOURISM AND PROTECTED AREAS IN COSTA RICA: CONFRONTATION OR CONCILIATION}

\author{
Gilbert Vargas Ulate*
}

RESUMEN

El Sistema de Áreas de Conservación de Costa Rica (SINAC) constituye el destino favorito de los turistas durante su estadía en nuestro país, además de ser el destino lógico para el turismo nacional. Su uso por parte de los turistas genera un dilema; por un lado genera beneficios económicos para diferentes sectores de la población, pero por otro, la actividad turística también afecta las iniciativas de conservación in situ, son estas relaciones de entendimiento y enfrentamiento las que se analizan en este estudio.

PALABRAS CLAVE: COSTA RICA * TURISMO * CONSERVACIÓN DE LA NATURALEZA * RECURSOS PROTEGIDOS * IMPACTO DEL TURISMO * TURISMO RESPONSABLE * GEOGRAFÍA DEL TURISMO

\section{ABSTRACT}

The Conservation Areas System (SINAC, in Spanish) of Costa Rica constitutes the favorite destination of tourists during their stay in our country, as well is a logic destination for national tourism. Their use for tourism create a dilemma; on one hand are the economic benefits generated for different sectors of population, but on the other hand, tourism has an effect on the in situ conservation initiatives. These conflicting, relations are analyzed in this study.

KEYWORDS: COSTA RICA * TOURISM * NATURE CONSERVATION * PROTECTED RESOURSES * TOURISM IMPACT * RESPONSIBLE TOURISM * TOURISM GEOGRAPHY

Rica.

gilberto.vargasulate@ucr.ac.cr 


\section{INTRODUCCIÓN}

Costa Rica es reconocida mundialmente por sus acciones de conservación, basadas en la creación de un muy buen sistema de áreas protegidas, es por eso, que el país decidió hace cerca de dos décadas utilizar la naturaleza como eje central del producto turístico nacional. Sea como visita a parques nacionales, a reservas privadas, a la playa, a hacer rafting o a observar aves. Le estamos ofreciendo naturaleza al visitante.

Las áreas protegidas son el destino favorito de los turistas durante su estadía en nuestro país, además de ser el destino lógico para el turismo nacional. Su uso por parte de los turistas genera un dilema; por un lado, genera beneficios económicos para diferentes sectores de la población, pero por otro, la actividad turística también afecta las iniciativas de conservación in situ.

Para llegar a un acuerdo entre turismo y naturaleza es necesario entender los patrones de visita, para guiar las decisiones sobre cuantos recursos deben ser asignados para el manejo de las áreas protegidas, para ofrecer un mayor número de opciones de visita y para ayudar a desarrollar planes para evitar impactos negativos en los ecosistemas naturales por una sobre carga del espacio.

Entender los patrones de visita, permite valorar el grado de satisfacción del turista, ya que su satisfacción no sólo depende del atractivo natural, sino de la comodidad con que lo hace, eso significa disponer de servicios sanitarios limpios, agua potable, caminos de acceso en buen estado y disponibilidad de información. Con lograr un excelente grado de satisfacción, el turista se convierte en el principal promotor del país como destino de la naturaleza.

\section{EL TURISMO EN ESPACIOS NATURALES}

El turista demanda cada vez mayores servicios $y$ posibilidades para pasar sus vacaciones de forma más activa y atractiva. Estas nuevas demandas turísticas tienen un interés creciente en el contacto con la naturaleza, que se traduce en una mayor sensibilidad hacia las buenas condiciones ambientales de los sitios donde realiza sus vacaciones.

En el sector turístico se comienza a percibir conductas de cambio, cuando el visitante solicita servicios que las grandes urbes y el crecimiento industrial les ha privado y sólo el contacto directo con la naturaleza se los puede dar (Organización Mundial del Turismo, 2005). A partir de 1990, el turista pide cada vez más lo auténtico y natural del sitio que visita, realmente quiere conocer lo que es $y$ no simpatiza con los lugares artificialmente bellos, siendo atraído por los paisajes exóticos del medio intertropical.

El perfil del turista que visita la naturaleza no puede considerarse como homogéneo, en la medida en que se trata de una clase de turismo cada vez más difundido, que abarca desde amplias sectores de la población motivados simplemente por la "moda ecológica" y la necesidad e interés que nace del mercadeo para disfrutar sus vacaciones en entornos naturales poco alterados, de gran belleza paisajística y abundante riqueza en flora y fauna, hasta los turistas que sí sienten una verdadera conciencia ambiental y demandan un mayor nivel de exigencia sobre aspectos relativos a la calidad medioambiental $y$ disfrutan en forma plena el contacto con las áreas silvestres, su observación y conservación.

Ambos grupos presentan una demanda diferente, pero comparten el interés por un destino común. Entre ambos segmentos de demanda se puede encontrar un conjunto muy heterogéneo de visitantes atraídos por la naturaleza en muy diverso grado. Cada segmento requiere un tipo particular de actividad turística que hay que identificar $y$ adaptar en cada caso (Wearing, 2000).

El turismo de naturaleza se puede dividir en varios tipos, e incluso subtipos, atendiendo a la conducta de los turistas en relación al medio, su actitud en relación a su propia presencia y comportamiento, su gama de preferencias y expectativas, su grado de satisfacción en relación con las condiciones naturales de los escenarios visitados y la mayor o menor existencia de áreas de uso público en los espacios naturales protegidos (De las Heras, 1999). 
En este sentido, se pueden distinguir los siguientes grupos de turistas de naturaleza o ecoturistas:

1. El turista de naturaleza casual es la categoría integrada por turistas que visitan un espacio natural protegido por casualidad, sin ser conscientes, en muchos casos, ni tan siquiera de que el lugar donde están es un espacio de estas características. Se caracterizan por poseer una escasa sensibilidad ambiental y la motivación que les ha llevado a realizar la visita no está relacionada con las características ecológicas del espacio.

2. El turista de naturaleza ocasional es aquel que es atraído por la belleza de un paisaje, por la posibilidad de ver en libertad determinada especie animal, de conocer una etnia o una cultura o por un espacio natural con una gran tradición turística.

Su visita obedece más bien a una necesidad creada por las propias agencias de viajes para favorecer una visita que de otra forma quizás no se hubiese producido. Se trata de turistas que disfrutan de la naturaleza como una pequeña parte de un viaje más amplio, cuya objetivo es el entretenimiento y a los que se ofrecen paquetes opcionales por un día u horas para visitar un espacio natural protegido con un atractivo admirable que debe de aprovechar al estar tan cerca.

3. El turista de naturaleza vocacional es un grupo con un amplio espectro de intereses que los acerca a la naturaleza. Se trata de un turista que valora, cada vez en mayor medida, la diversidad y belleza del paisaje, el descubrimiento de sitios diferentes, la ausencia de contaminación, la existencia de información sobre lugares de interés $y$ actividades a realizar, la relación con la población local, la práctica de actividades deportivas, entre otras.

Es un turista por lo general de áreas urbanas, cada vez más motivado hacia la naturaleza por propia educación y por la influencia que ejercen los medios de comunicación, y que se deja educar fácilmente porque muestra una apertura.

4. El turista de naturaleza bien informado tiene una elevada preparación, aunque no son profesionales ligados a las ciencias de la tierra, sí conocen en detalle aspectos relacionados con el relieve, las aguas, la flora y la fauna del área gracias a que se ha documentado a conciencia antes de realizar la visita.

Se trata de personas que realizan viajes específicamente para visitar espacios naturales protegidos $y$ que desean entender $y$ participar de la historia natural y cultural del área que visitan. El ocio para ellos es la naturaleza misma y busca en ella conocer y practicar actividades específicas como la observación de aves, murciélagos, reptiles, mamíferos silvestres o practicar el buceo.

5. El turista de naturaleza científico es un tipo muy limitado, en lo que respecta a su comercialización. Se trata de un tipo de turismo especialmente vinculado a científicos, investigadores y estudiantes interesados en conocer aspectos ecológicos y ambientales de los espacios naturales protegidos, y que generalmente, visitan las zonas más restringidas. La motivación principal no es de tipo vacacional sino el cumplimiento del tema objeto de estudio (Boullón, 2002 y Boo, 1992).

El turismo practicado en espacios naturales incluye todo turismo dependiente del uso de recursos naturales en ecosistemas en equilibrio o poco alterados; como cuerpos de agua, vegetación $y$ vida silvestre e incluyen actividades que van desde caminatas, aventura, observación de especies entre otras, por lo tanto la diversidad biológica y cultural constituye la base del atractivo turístico.

El turismo natural o ecoturismo se diferencia del turismo convencional en las motivaciones $y$ conductas de los turistas y por la singularidad de los recursos, que tienen un alto valor ecológico y paisajístico que en la mayoría de los casos son espacios naturales protegidos. El turismo en espacios naturales debe obligatoriamente ser de bajo impacto ambiental, muy cuidadoso con la naturaleza, y con la población local (Drumm y Moore, 2002).

El turismo practicado en Costa Rica busca lo natural y lo original y aquí la naturaleza adquiere gran valor ecológico y económico 
al ofrecerla como atractivo natural. El sistema de áreas protegidas de nuestro país ofrece al turista una gran variedad de atractivos naturales como playas, paisajes naturales en equilibrio, biodiversidad, paisajes de montañas, ríos, acantilados, lagos de origen glaciar o volcánico, manglares, aves, fauna silvestre, fauna marina y una gran variedad de tipos de vegetación tropical.

\section{EL SISTEMA DE ÁREAS PROTEGIDAS EN COSTA RICA}

Toda sociedad en su relación con la naturaleza utiliza los recursos naturales para satisfacer sus necesidades, pero en la mayoría de las ocasiones se establece un mal uso de los recursos y se crea un impacto negativo, es en este momento que aparece la preocupación por proteger los recursos. En nuestro país esta preocupación nació desde el momento en que se alcanza la vida independiente.

De 1821 a 1850 se dio una legislación conservacionista preliminar que pretendió pro- teger principalmente las aguas de las acequias, las cuales eran usadas por los centros poblados para todas las necesidades básicas. Igualmente se reguló la extracción de madera utilizada como leña y se estimuló a la población a plantar especies maderables en cercos vivos. Todas estas medidas tenían que ser acatadas por las municipalidades (Vargas, 1993).

En la segunda mitad del siglo XIX, se abandonó prácticamente la promulgación de decretos y leyes conservacionistas para favorecer el desarrollo de la hacienda cafetalera y por este abandono es que aparecen los primeros focos de contaminación en las aguas de los ríos al verter los beneficios de café, las aguas servidas y la broza del café.

La creación de leyes y decretos continúo en el siglo Xx y entre 1900 y 1940, se dio una abundante jurisprudencia en materia ambiental, pero lamentablemente esta no fue acompañada con la creación de instituciones que ejecutaran e hicieran cumplir lo dispuesto en las leyes y decretos (Vargas, 1993; Porras, 1980 y 1981). El cuadro 1 resume parte de esta legislación dada en Costa Rica.

CUADRO 1

LEYES Y DECRETOS EN MATERIA AMBIENTAL DADOS EN COSTA RICA ENTRE 1888 Y 1940

\begin{tabular}{cc}
\hline AÑO & LEYES Y DECRETOS \\
\hline 1888 & $\begin{array}{c}\text { Decreto que declara inalienable una zona de } 2 \mathrm{~km} \text { a los lados del volcán Barva } \\
\text { Decreto para declarar nulas las demandas de inscripción de terrenos en el volcán } \\
\text { Barva }\end{array}$ \\
1889 & $\begin{array}{c}\text { Proyecto para crear un Código ambiental } \\
1903\end{array}$ \\
1906 & Ley de guardabosques \\
1909 & Ley de quemas \\
1923 & Ley de reforestación \\
1935 & Ley de explotación de bosques \\
1939 & Ley de terrenos baldíos \\
1939 & Decreto de protección del río Banano para proteger las fuentes de agua de Limón \\
1939 & Ley de protección de 2 km en los alrededores de los volcanes Poás, Barva, Irazú y \\
& los cerros Zurquí \\
\hline
\end{tabular}

Fuente: Vargas, 1993 y González, 1980. 
Las primeras denuncias en contra de la contaminación y la deforestación en el país y las primeras manifestaciones conservacionistas y de protección de los recursos naturales en Costa Rica se dieron a inicios del siglo Xx, cuando grandes naturalistas como Anastasio Alfaro, Alberto Manuel Brenes, Carlos Wercklé, Phillip y Amelia Calvert, Henrie Pittier, Vicente Lachner y José Fidel Tristán manifestaron ante el gobierno su preocupación por la tala de árboles sin previsión, sin control y sin criterio (Vargas, 1993).

Antes de 1940, el concepto de espacio natural protegido como categoría de manejo no existía en la legislación costarricense (González, 1981). Es a partir, de la participación de Costa Rica en la Convención de Washington de 1942, sobre la "Protección de la flora, fauna y bellezas escénicas de los países de América" que se inició el uso del concepto de espacio natural protegido y se crearon por primera vez en el país, las categorías de manejo de parque nacional, reserva nacional, monumentos naturales y reservas de espacios vírgenes (González, 1981).

Dieciséis años más tarde, en 1958, por ley nro. 3763 se ratifica dicha convención y se establecieron nuevos espacios protegidos como los parques nacionales volcán Poás, Turrialba e Irazú, cuya administración se le encargó al Instituto Costarricense de Turismo y en 1963, se estableció la Reserva Natural Absoluta Cabo Blanco.

Los primeros espacios protegidos que se crearon en Costa Rica fueron la isla del Caño que en 1935 se declaró como área de conservación por encontrarse en ella el mayor cementerio indígena del país. Luego en 1955 se declaran parques nacionales el volcán Poás y el volcán Irazú y en 1961, el Instituto Costarricense de Electricidad creó la primera reserva Forestal en Río Macho (Vargas, 1993).

En 1969, se promulgó la primera Ley Forestal y con ella se crea el Servicio de Parques Nacionales y la Dirección General Forestal. El Servicio de Parques Nacionales tuvo bajo su responsabilidad la administración de los parques nacionales $y$ las reservas biológicas y a la Dirección General Forestal le correspondió la administración de las reservas forestales y las zonas protectoras. El Departamento de Vida Silvestre fue creado en 1970 y fue el responsable de administrar los refugios de vida silvestre (Figura 1).

FIGURA 1

ESTRUCTURA ADMINISTRATIVA DE LOS ESPACIOS PROTEGIDOS DE 1969 A 1986

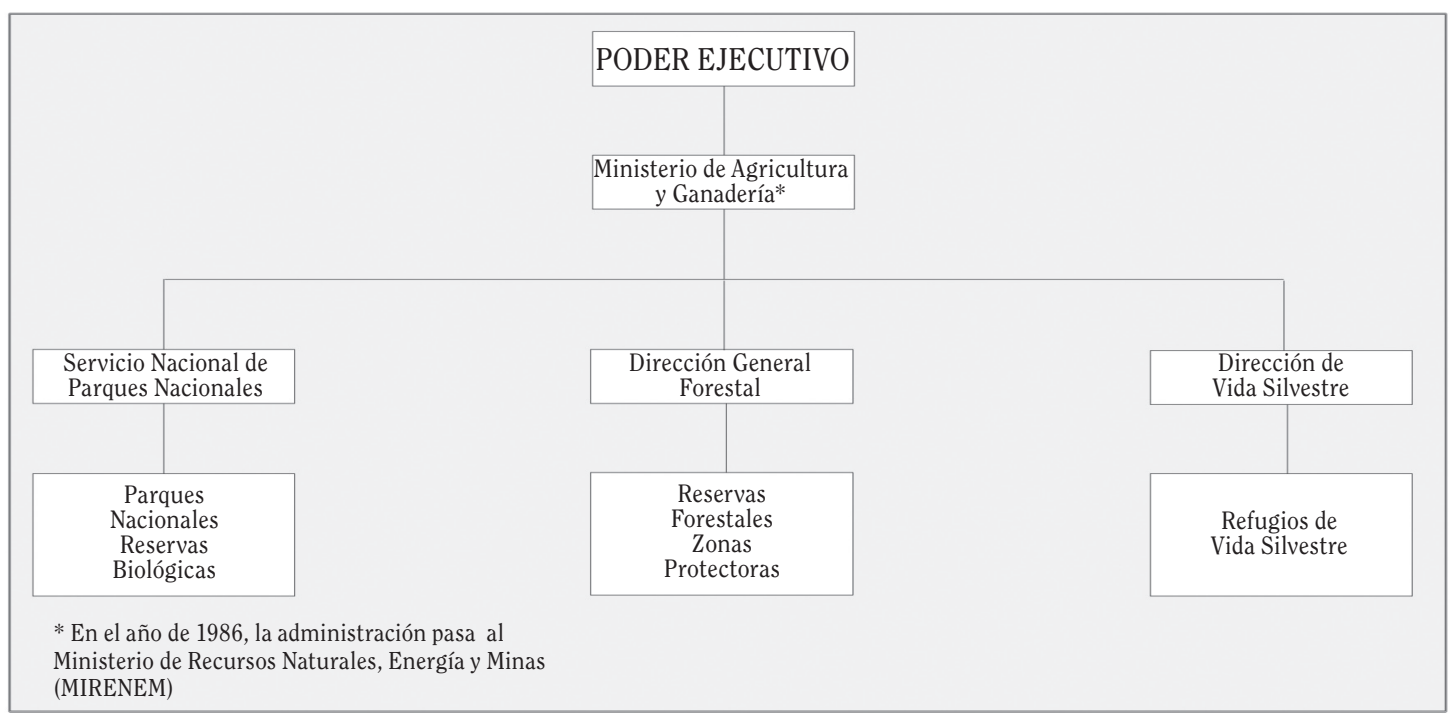


En 1986, se creó el Ministerio de Recursos Naturales, Energía y Minas (MIRENEM), que luego en 1992, cambió de nombre a Ministerio del Ambiente y Energía (MINAE). Este cambio no solo marcó una denominación diferente del ministerio, sino que se inicio una nueva forma de administrar los recursos naturales en Costa Rica, más integradora, sistemática y descentralizada, con lo que las diversas regiones adquieren más poder de decisión.

Con la promulgación de la Ley de Biodiversidad, en 1995 se fusionan las tres antiguas formas de organización que tuvieron a su cargo la responsabilidad, la administración y tutela de las diferentes categorías de manejo de áreas silvestres protegidas del país, a saber, la Dirección General Forestal, la Dirección General de Vida Silvestre y el Servicio de Parques Nacionales. De esta manera el MINAE establece oficialmente el Sistema Nacional de Áreas de Conservación (SINAC).

El Sistema Nacional de Áreas de Conservación de Costa Rica (SINAC) es un sistema de gestión institucional desconcentrado $y$ participativo que integra las competencias en materia forestal, de vida silvestre y áreas silvestres protegidas del MINAE (Figura 2).

El objetivo del SINAC es dictar políticas, planificar y ejecutar procesos dirigidos a lograr la sostenibilidad en el manejo de los recursos naturales de Costa Rica. El SINAC está constituido por once subsistemas denominados áreas de conservación que son las siguientes: Guanacaste, Tempisque, Arenal Tempisque, Arenal Huetar Norte, Cordillera Volcánica Central, Pacífico Central, Osa, La Amistad Pacífico, La Amistad Caribe, Tortuguero e Isla del Coco (Figura 3).

FIGURA 2

ESTRUCTURA ADMINISTRATIVA DE LOS ESPACIOS PROTEGIDOS DE 1986 A LA ACTUALIDAD

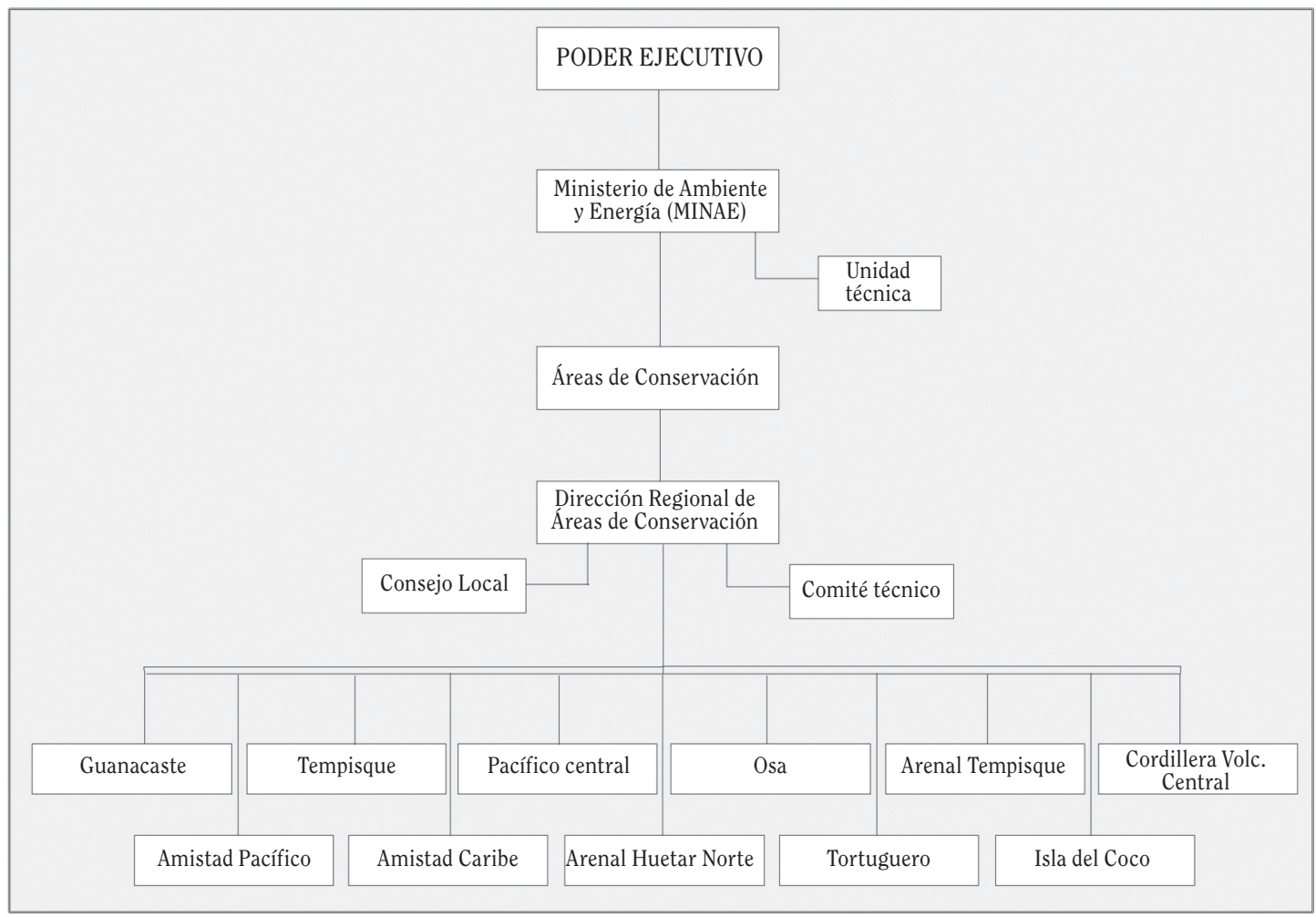


FIGURA 3

MAPA DE ÁREAS DE CONSERVACIÓN

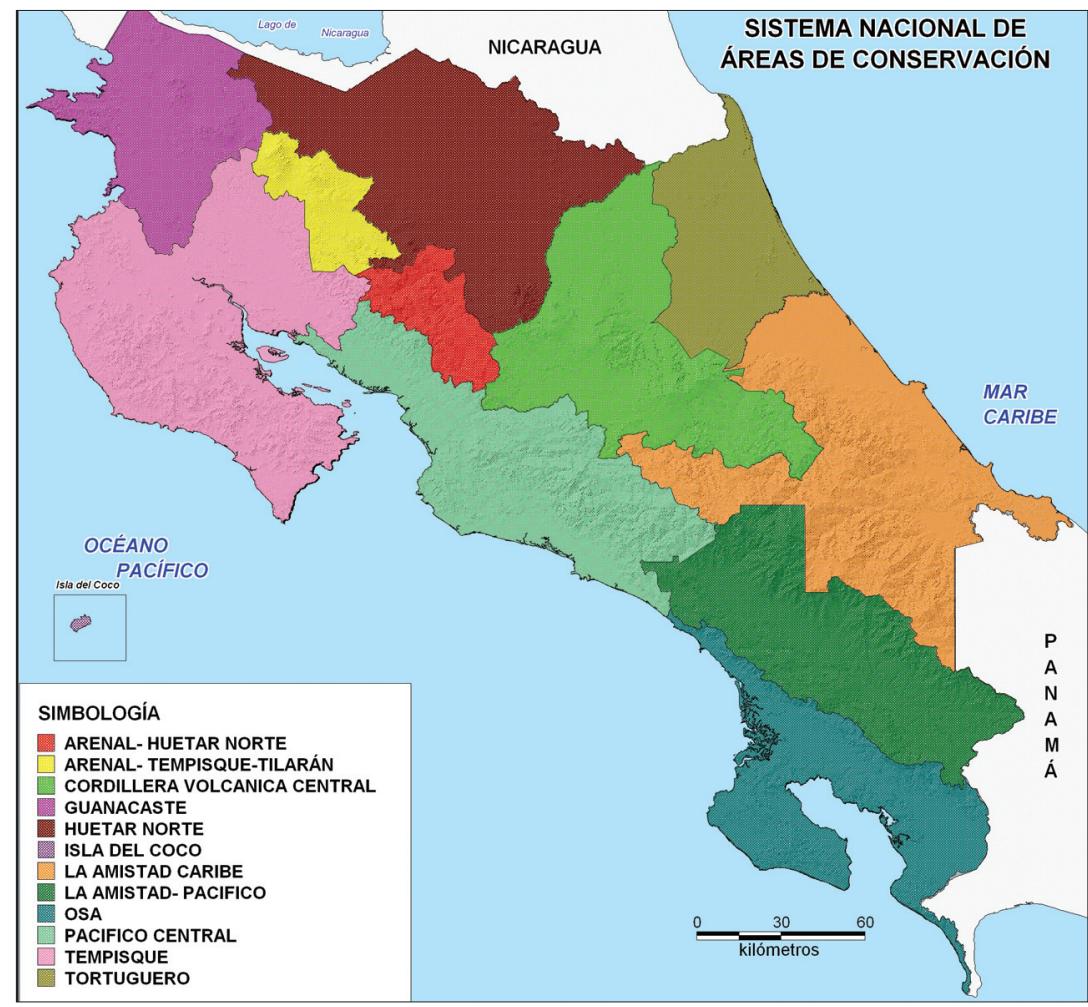

Dentro de las áreas de conservación se establecen 8 categorías de manejo para las áreas silvestres protegidas. Estas categorías de manejo son: los parques nacionales, las reservas biológicas, los monumentos nacionales, los refugios de vida silvestre, las zonas protectoras, las reservas forestales, los humedales y los monumentos naturales (Figura 4).
El parque nacional es un área con rasgos de carácter singular de interés nacional o internacional que incluye muestras representativas de ecosistemas de significación nacional, con poca evidencia de actividad humana que ofrecen importantes atractivos para los visitantes $y$ tienen capacidad para un uso recreativo $y$ educativo en forma controlada (Fotos). 
FIGURA 4

MAPA DE CATEGORÍAS DE MANEJO
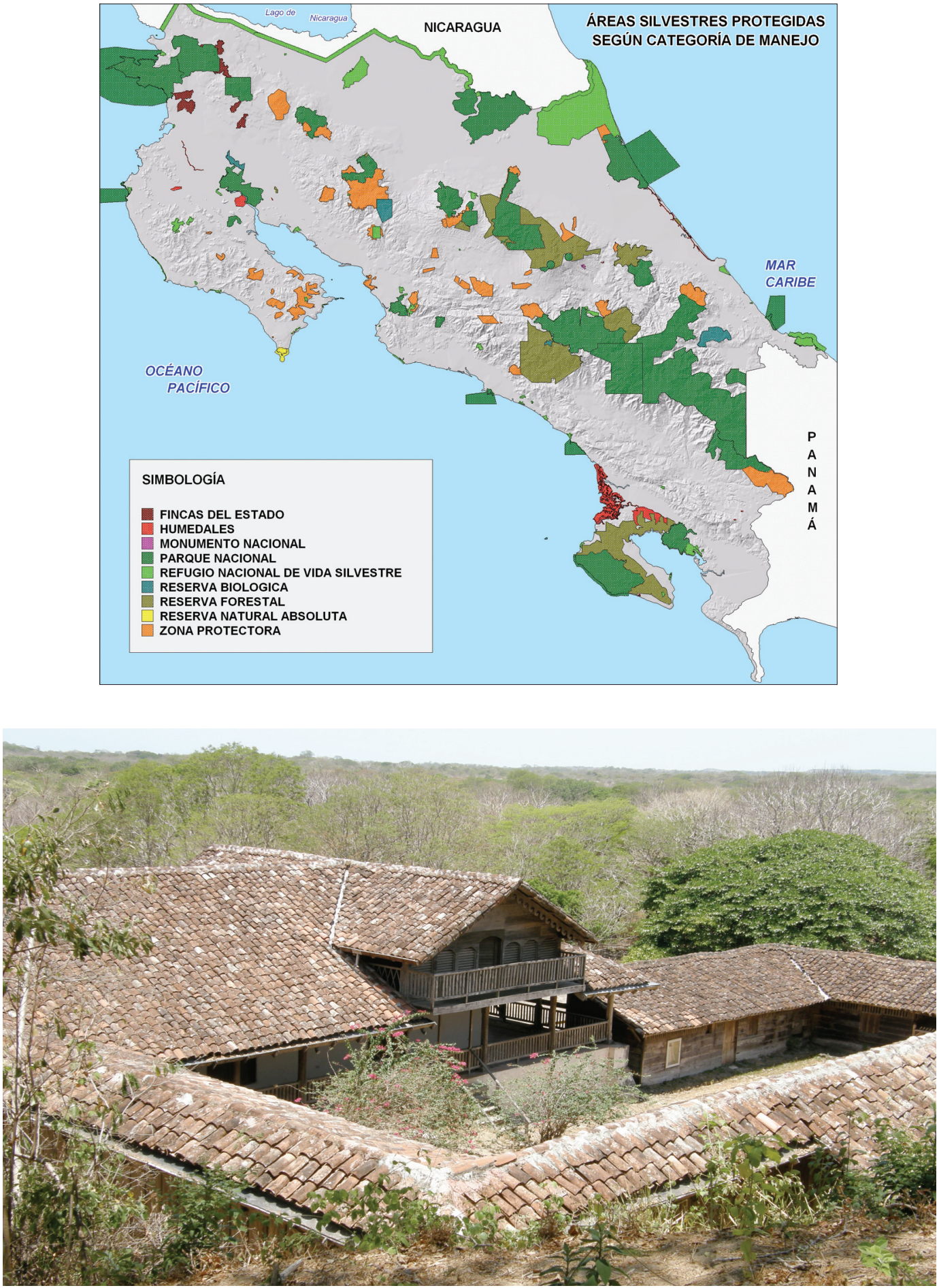

Foto 1. Monumento Histórico Casona Santa Rosa creado en el año de 1970 


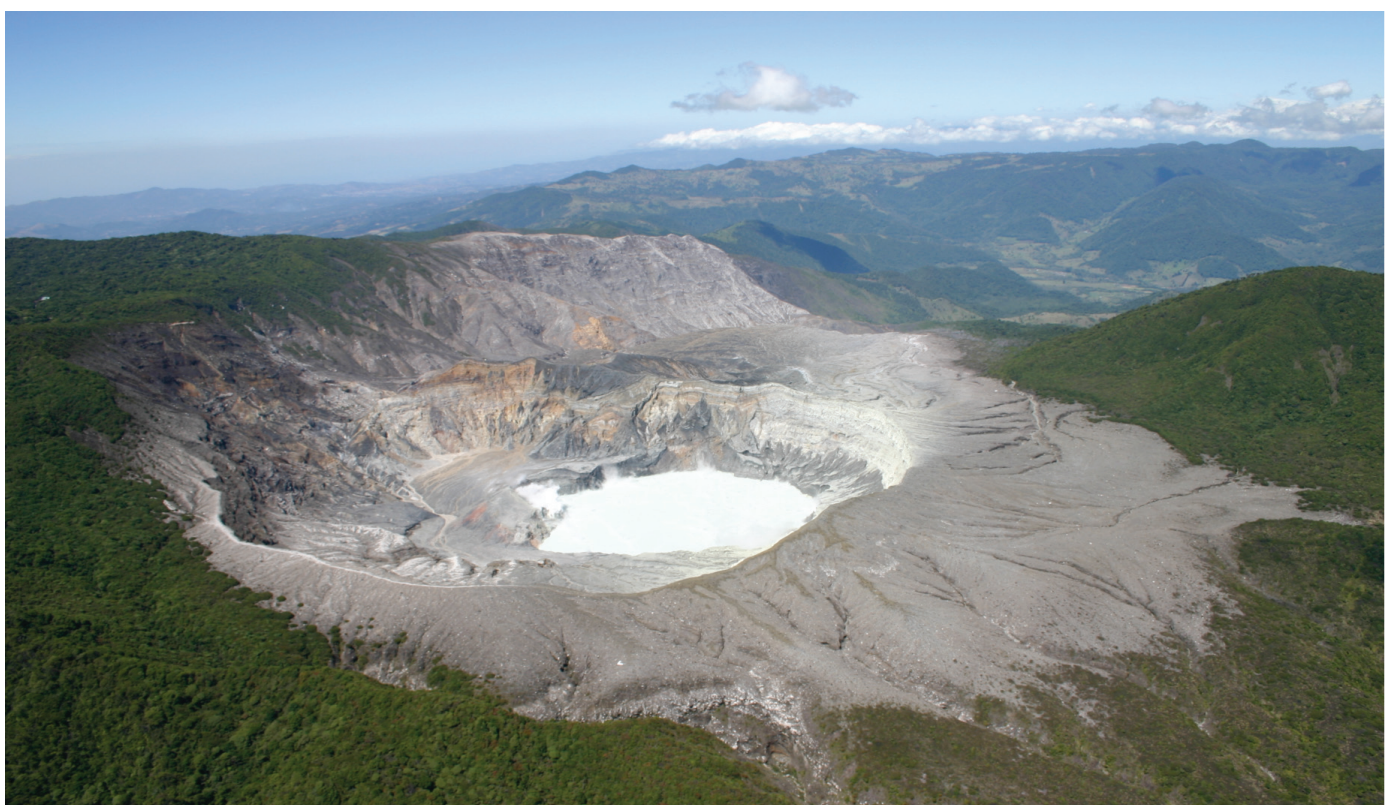

Foto 2. Parque Nacional Volcán Poás

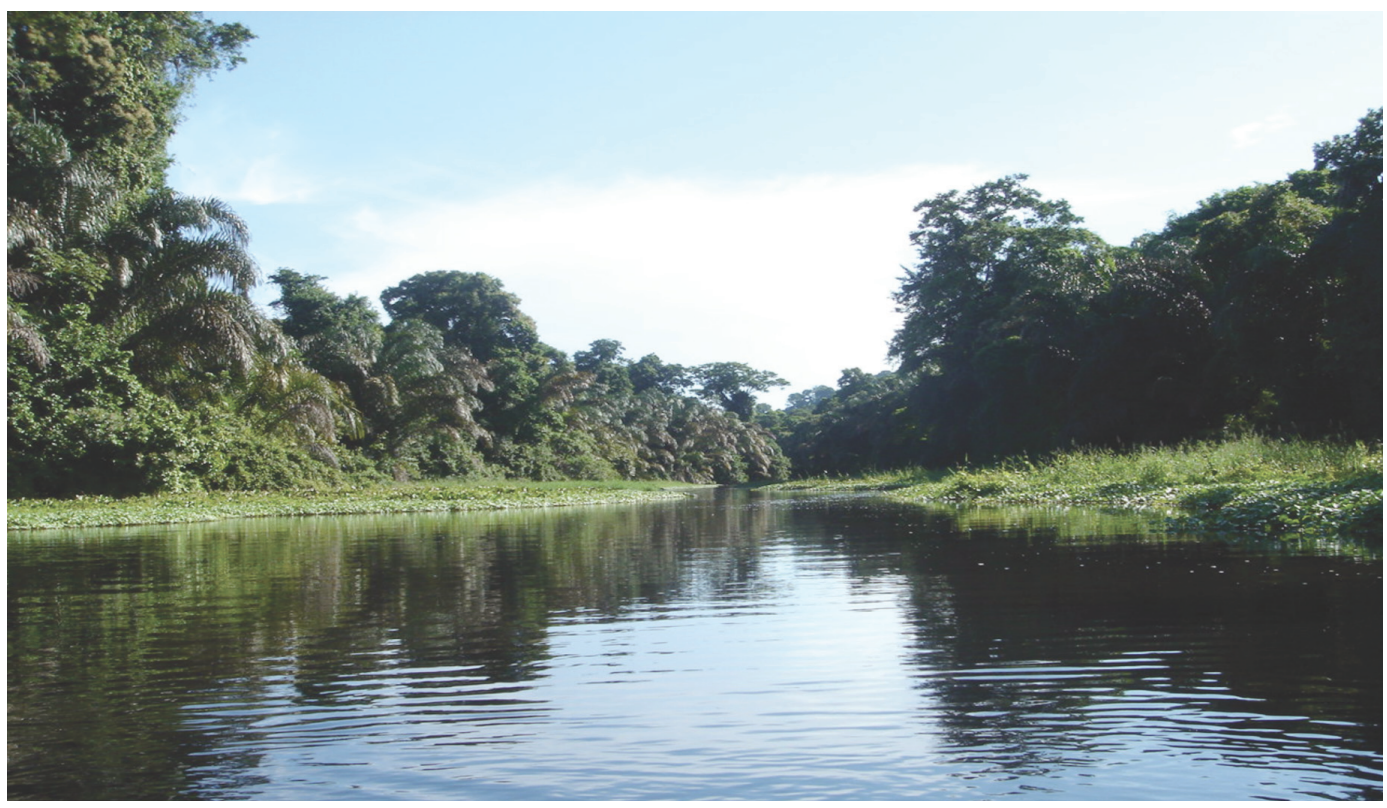

Foto 3. Parque Nacional Tortuguero 


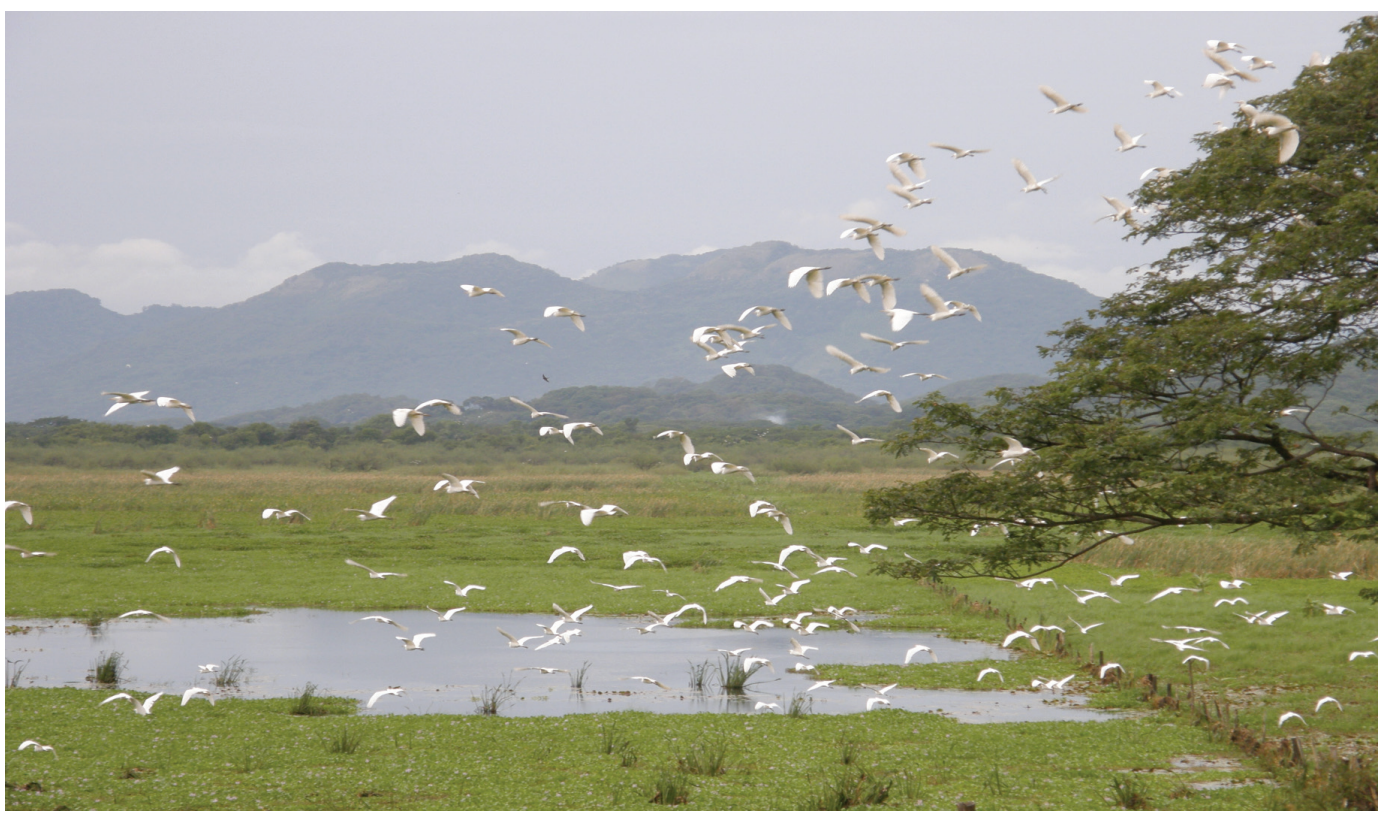

Foto 4. Parque Nacional Palo Verde

La reserva biológica es un territorio inalterado, que contiene ecosistemas y especies de flora y fauna extremadamente vulnerables, en la cual los procesos ecológicos han podido seguir su curso natural con un mínimo de interferencia humana. En ella, únicamente se autorizan actividades de investigación y educación.

La actividad turística se practica en las reservas biológicas de Monteverde, Isla del Caño, Lomas de Barbudal e Hitoy Cerere, lo cual no es conveniente por incumplir lo establecido en la Ley de Biodiversidad y por llevarse a cabo en ecosistemas muy frágiles.

Los monumentos nacionales pueden tener dentro de sus límites un recurso cultural, sea histórico o arqueológico sobresaliente, de importancia nacional e internacional debido a sus características únicas o de especial interés, su extensión depende del tamaño del recurso que se desea conservar y cuánto terreno adyacente se necesite para asegurar su protección $y$ el manejo adecuados. Dos ejemplos son el monumento Guayabo y el monumento casona Santa Rosa.

Los refugios de vida silvestre son espacios naturales que por sus condiciones geográficas y biológicas protegen ecosistemas especiales $y$ de variada o exclusiva biodiversidad, para la protección e investigación de la flora y la fauna silvestre; en especial de las que se encuentren en vías de extinción.

En el país existen tres clases de refugios nacionales de vida silvestre: los refugios de propiedad estatal donde las terrenos declarados como tales pertenecen en su totalidad al Estado y están inscritos en el registro de la propiedad como tales; los refugios de propiedad mixta que mantienen tierras que pertenecen en parte al Estado y otras son de propiedad particular y los refugios propiedad privada que pertenecen en su totalidad a particulares.

Las zonas protectoras están formadas por áreas de bosques y terrenos de aptitud forestal, donde el objetivo principal sea la protección del suelo, la regulación del régimen hidrológico y la conservación del ambiente y de las cuencas hidrográficas.

Las reservas forestales son terrenos, en su mayoría de aptitud forestal, apropiados para la producción de madera, en las cuales se ejecutan acciones de manejo con criterios de sostenibilidad.

Los humedales son ecosistemas con dependencia de regímenes acuáticos, naturales 
o artificiales, permanentes o temporales, lénticos o lóticos, dulces, salobres o salados, incluyendo las extensiones marinas hasta el límite posterior de fanerógamas marinas o arrecifes de coral o, en su ausencia, hasta seis metros de profundidad en marea baja.

Los monumentos naturales contienen uno o varios elementos naturales de impor- tancia nacional. Consisten en lugares $\mathrm{u}$ objetos naturales que, por su carácter único o excepcional, su belleza escénica, o su valor científico, se resuelva incorporarlos a un régimen de protección, esta categoría de manejo será creada por el Ministerio del Ambiente y Energía y administrada por las municipalidades respectivas (Cuadro 2).

\section{CUADRO 2 \\ ÁREAS DE CONSERVACIÓN Y CATEGORÍAS DE MANEJO EN COSTA RICA}

\begin{tabular}{|c|c|}
\hline $\begin{array}{l}\text { ÁREAS DE } \\
\text { CONSERVACIÓN }\end{array}$ & CATEGORÍAS DE MANEJO \\
\hline GUANACASTE & $\begin{array}{l}\text { Parques Nacionales: Rincón de la Vieja, Santa Rosa, Guanacaste. Refugios de vida } \\
\text { silvestre: Iguanita, bahía Junquillal. Reserva natural absoluta Nicolás Wessberg. } \\
\text { Humedales: riberino Zapandí. Corredor biológico fronterizo }\end{array}$ \\
\hline TEMPISQUE & $\begin{array}{l}\text { Parques Nacionales: marino Las Baulas, Barra Honda, Diriá. Reservas biológicas: Isla } \\
\text { Guayabo, isla Negrito, Romelia. Refugios de vida silvestre: Costa Esmeralda, Tamarindo, } \\
\text { Mata redonda, isla San Lucas, Ostional, Werner Sauter, Camaronal, Curú. Reserva } \\
\text { natural absoluta Cabo Blanco. Zonas protectoras: Nosara, península de Nicoya, Cerro de } \\
\text { La Cruz. Humedales: riberino Zapandí, palustrito Corral de Piedra. }\end{array}$ \\
\hline PACÍFICO CENTRAL & $\begin{array}{l}\text { Parques Nacionales: Carara, Manuel Antonio. Reservas biológicas: isla de Pájaros. } \\
\text { Refugios de vida silvestre: Peñas Blancas, La Ensenada, isla San Lucas, Punta Leona, } \\
\text { playa Hermosa, Portalón, finca Barú, Transilvania, Páramo, cataratas de cerro Redondo, } \\
\text { Surtubal, Fernando Castro Blanco, hacienda La Avellana, Peñas Blancas. Zonas } \\
\text { protectoras: Tivives, Los Santos, Quebrada Rosario, Caraigres, cerros de Escazú, } \\
\text { Quitirrisí, El Rodeo, cerros de Turrubares, cerro el Chompipe, Montes de Oro. }\end{array}$ \\
\hline LA AMISTAD-PACÍFICO & $\begin{array}{l}\text { Parques Nacionales: Internacional La Amistad, Chirripó, Tapantí-cerro de La Muerte. } \\
\text { Refugios de vida silvestre: Joseph S. Friedman. Zonas protectoras: Las Tablas, río } \\
\text { Navarro-Sombrero. Reserva forestal río Macho. Humedales: San Vito, palustrito laguna } \\
\text { de Paraguas. }\end{array}$ \\
\hline OSA & $\begin{array}{l}\text { Parques Nacionales: Marino Ballena, Piedras Blancas, Corcovado. Refugios de Vida } \\
\text { Silvestre: Osa, río Oro, Hacienda Copano, Pejepero, río Piro, Preciosa Platanares, Golfito, } \\
\text { Rancho La Merced. Reserva Forestal Golfo Dulce. } \\
\text { Humedales: Lacustrino Pejeperrito, nacional Térraba-Sierpe. }\end{array}$ \\
\hline HUETAR NORTE & $\begin{array}{l}\text { Parques Nacionales: Juan Castro Blanco, Arenal. Refugios de vida silvestre: Corredor } \\
\text { fronterizo, Laguna Las Camelias, Caño Negro. Reservas Forestales: cerro El Jardín, La } \\
\text { Cureña. Humedales: palustrino laguna Maquenque, lacustrino Tamborcillo. }\end{array}$ \\
\hline ARENAL-TEMPISQUE & $\begin{array}{l}\text { Parques Nacionales: volcán Tenorio, Palo Verde. Reserva biológica Lomas de Barbudal. } \\
\text { Zonas protectoras: Tenorio, Arenal-Monteverde, cuenca del río Abangares, Miravalles. } \\
\text { Reserva Forestal Taboga, Cipandi. Humedales: laguna Madrigal. }\end{array}$ \\
\hline LA AMISTAD-CARIBE & $\begin{array}{l}\text { Parques Nacionales: internacional La Amistad, Cahuita, Barbilla. Reserva biológica Hitoy } \\
\text { Cerere. Refugios de vida silvestre: Limoncito, Gandoca-Manzanillo. } \\
\text { Reservas Forestales: Pacuare-Matina, río Pacuare. Zonas protectoras: río Banano, } \\
\text { cuenca del río Siquirres. Humedales: lacustrino Bonilla y Bonillita, nacional Cariari. }\end{array}$ \\
\hline TORTUGUERO & $\begin{array}{l}\text { Parque Nacional Tortuguero. Refugios de vida silvestre: Barra del Colorado,Corredor } \\
\text { fronterizo. Zonas protectoras: Tortuguero, acuíferos Guácimo y Pococí. }\end{array}$ \\
\hline
\end{tabular}


CUADRO 2

ÁREAS DE CONSERVACIÓN Y CATEGORÍAS DE MANEJO EN COSTA RICA (CONTINUACIÓN)

\begin{tabular}{ll}
\hline $\begin{array}{l}\text { ÁREAS DE } \\
\text { CONSERVACIÓN }\end{array}$ & \multicolumn{1}{c}{ CATEGORÍAS DE MANEJO } \\
\hline VOLCÁNICA CENTRAL & $\begin{array}{l}\text { Parques Nacionales: volcán Irazú, volcán Poás, Volcán Turrialba, Braulio Carrillo. Reserva } \\
\text { biológica Alberto Manuel Brenes. Zonas protectoras: río Grande, cerro Atenas, cerros } \\
\text { La Carpintera, La Marta, cuenca del río Tuis, La Selva, río Toro, río Tiribí. Reservas } \\
\text { forestales: cordillera volcánica Central, Grecia. Refugios de vida silvestres: Bosque Alegre, } \\
\text { Cerro Dantas. }\end{array}$ \\
\hline MARINO ISLA DEL COCO & $\begin{array}{l}\text { Sitio Patrimonio Natural de la Humanidad. UNESCO. 1967. Humedal de importancia } \\
\text { internacional. (RAMSAR). 1998. Sitio histórico cultural. Ministerio de Cultura. } 2002 .\end{array}$ \\
\hline
\end{tabular}

Fuente. Mapa de áreas silvestres protegidas. SINAC. 2007.

La Reserva absoluta es una categoría de manejo especial, creada en 1963 por el matrimonio sueco de Nicolás Wessberg y Karen Mogensen quienes protegieron en forma absoluta y recuperaron el bosque seco de Cabo Blanco y al morir, ellos solicitaron que el área pasará al Estado bajo la misma categoría (Vargas, 2006). También, existen categorías de manejo internacionales como la reserva de la biosfera y los sitios RAMSAR que protegen humedales.
Los corredores biológicos no constituyen una categoría de manejo oficial, sino que se les considera una forma de conservación que constituyen extensiones de terreno generalmente de propiedad privada, cuya función principal es interconectar áreas silvestres protegidas para posibilitar tanto la migración como la dispersión de especies de flora y fauna silvestre $y$ en esta forma asegurar la conservación de las mismas.

El cuadro 3 presenta la superficie y el porcentaje de las áreas protegidas por categoría de manejo.

CUADRO 3

SUPERFICIE DE LAS ÁREAS PROTEGIDAS POR CATEGORÍA DE MANEJO

\begin{tabular}{lccc}
\hline CATEGORÍA & CANTIDAD & SUPERFICIE EN HECTÁREAS & $\begin{array}{c}\text { PORCENTAJE DEL } \\
\text { TERRITORIO NACIONAL }\end{array}$ \\
\hline Parques nacionales & 25 & 623771 & 12,33 \\
Reservas biológicas & 8 & 21674 & 0,42 \\
Zonas protectoras & 32 & 155817 & 3,06 \\
Reservas forestales & 11 & 227834 & 4,47 \\
Refugios de vida silvestre & 58 & 180035 & 3,53 \\
Humedales (incluye manglares) & 15 & 77869 & 1,53 \\
Otras categorías & 12 & 17306 & 0,34 \\
TOTAL & 161 & 1304306 & 25,58 \\
\hline
\end{tabular}

Fuente: SINAC. 2007. 
La Ley número 156, del 13 de agosto de 2008, conocida como Ley de Fortalecimiento y Modernización de las Entidades Públicas del Sector Telecomunicaciones establece que al no existir un verdadero sector de telecomunicaciones le corresponde al MINAE asumir esta función por lo que pasa a llamarse MINAET (Ministerio del Ambiente, Energía y Telecomunicaciones).

Las áreas silvestres protegidas generan una serie de beneficios para el país. Entre los más importantes podemos mencionar:

\section{$\diamond$ Conservan la biodiversidad genética de} especies y de ecosistemas. Las áreas silvestres protegidas se han convertido en refugios para muchas especies de plantas $y$ animales en peligro de extinción. Once de las doce zonas de vida presentes en el país están representadas en estas áreas de conservación.

$\diamond$ Protegen el patrimonio cultural, histórico y arqueológico. En algunos parques nacionales y áreas se protegen sitios de gran valor histórico y cultural, reveladores de la historia de nuestra sociedad, de los cambios tecnológicos, de las costumbres y de los hábitos de nuestros antecesores.

$\diamond$ Conservar y proteger las cuencas hidrográficas. La conservación del bosque en las áreas silvestres protegidas, mantiene gran número de nacientes, quebradas y ríos que abastecen a los costarricenses del agua necesaria para el desarrollo de las actividades agrícolas, industriales, domésticas y la producción de energía hidroeléctrica.

$\diamond$ Proveen educación. Las áreas silvestres son las mejores aulas al aire libre. En estas, el visitante conoce los procesos naturales, aprende a apreciar la naturaleza $y$ a participar activamente en la tarea de conservación del ambiente.

$\diamond$ Permiten la investigación científica y monitoreo ambiental. Los recursos de las áreas silvestres son estudiados constantemente por científicos, quienes tienen el propósito de conocer los procesos ecológicos tendientes a mejorar la calidad de vida.

$\diamond$ Posibilitan la recreación y el turismo. Las áreas silvestres protegidas son especialmente atractivas para miles de personas nacionales y extranjeros, quienes las visitan atraídos por la enorme riqueza natural y cultural que conservan. Esta gran afluencia turística, en gran medida, ha contribuido a fortalecer la economía nacional.

$\diamond$ Propician el desarrollo rural. Es política institucional que los servicios y facilidades que requieren los turistas que visitan las áreas silvestres protegidas, los ofrezcan las comunidades vecinas a las áreas. Las vías de acceso se mejoran y se fomenta el comercio local.

Costa Rica ha sabido promover la gestión ambiental en el mundo mediante un sistema nacional de áreas protegidas que cubre más del 25\% del territorio nacional, la reducción de la deforestación y la aplicación de servicios ambientales, por lo que ha sido reconocida a nivel mundial como un país de grandes avances en la conservación de la biodiversidad y manejo sostenible de los recursos naturales. Según el Índice de Desempeño Ambiental (EPI) del 2008, por sus siglas en inglés y elaborado por el Yale Center for Environmental law and Policy de la Universidad de Yale coloca a Costa Rica en el primer lugar del continente americano $y$ el quinto en el mundo, después de Suiza, Suecia, Noruega y Finlandia por su conservación ambiental, aspecto que le favorece como promoción turística.

\section{TURISMO Y ÁREAS PROTEGIDAS EN COSTA RICA}

El interés del turismo por disfrutar y participar de la naturaleza, marca un cambio en la práctica del turismo que pasa del dominio del turismo tradicional al turismo de la naturaleza.

Esta preocupación por la naturaleza nace en los países desarrollados en 1949, con la creación del programa "El hombre y la biosfera", de la UNESCO. Posteriormente, a partir de 1968, aparecen las obras de enfoque conservacionista de Rene Dubois y Ward Barbara (1972), Paul R. Erlich (1960), Georges Borgstrom (1965), Rachel Carson (1969) y Kai Curry Lindahl (1974) quienes plantearon $y$ defendieron la tesis 
de frenar el crecimiento de la población por considerar que se llegaría a un momento donde los recursos serían insuficientes. También, criticaron fuertemente el crecimiento económico y consideraban que la degradación ambiental era causada por el ser humano que era su principal enemigo (Pérez Agote, 1982). De esta manera nace una conciencia social por los problemas ambientales como la contaminación, deforestación, erosión, así como por el hambre.

En junio de 1972, la Conferencia de Estocolmo, de las Naciones Unidas (ONU) produjo dos resultados muy importantes: El primero fue la creación del Programa de las Naciones Unidas para el Medio Ambiente (PNUMA) que inició los estudios sobre medio ambiente en el mundo y el segundo fue la declaración del "ecodesarrollo" de Maurice Strong como política oficial de la ONU. El ecodesarrollo partía de que el medio ambiente no puede mejorarse si hay pobreza y la forma de lograr un desarrollo era creando condiciones de vida adecuadas en los países subdesarrollados, por lo tanto, se debía tener una relación muy estrecha y equilibrada entre el crecimiento económico y la protección del ambiente (Tamanes, 1985).

Las políticas internacionales antes mencionadas influyeron en nuestro país por medio de dos eventos importantes que realizan una crítica y toma conciencia en la conservación y explotación de los recursos naturales en Costa Rica. Ellos son: el primer congreso nacional sobre los recursos naturales, realizado en la Universidad de Costa Rica, en 1974. Este congreso hizo un inventario de los principales problemas ambientales del país y planteó soluciones concretas a cada uno de los problemas analizados. Entre las recomendaciones dadas estaban el tener un mayor control del crecimiento urbano desordenado y llevar a cabo una creación ordenada de espacios protegidos.

El segundo evento fue el Simposio "La Costa Rica del año 2000", celebrado en 1977. Entre las propuestas del simposio sobresalía la creación del Instituto Nacional de Recursos Naturales (INDERENA), como una institución autónoma que tendría la responsabilidad de llevar a cabo la administración, gestión y control de todos los recursos naturales. Su creación pasó a la Asamblea Legislativa donde nunca fue objeto de estudio (Vargas, 1993).

En 1980, las Naciones Unidas por medio del PNUma y la Unión internacional para la Conservación de la Naturaleza (UICN) implementan la "Estrategia Mundial para la Conservación de la Naturaleza", una política mundial que se fundamentó en el desarrollo sostenible.

El desarrollo sostenible se basa en que el desarrollo y la conservación son equivalentes en cuanto a su importancia para la supervivencia humana y para el cumplimiento de las responsabilidades de las sociedades como depositarias de los recursos naturales que necesitan las generaciones futuras (PNUMA y UICN, 1980).

Esta política internacional nuevamente tiene influencia en Costa Rica, por medio de la creación de la "Estrategia de Conservación para el Desarrollo Sostenible" (ECODES), que se define como un proceso amplio y continuo para alcanzar un estilo de convivencia económica y social, compatible con el patrimonio natural que fuese perdurable y que no destruyera el potencial de los recursos naturales protegidos de Costa Rica (Vargas, 1993).

Esta conciencia ambiental nacida en organismos internacionales se puso en práctica en nuestro país desde 1950 y en especialmente después de la creación de la Ley Forestal en 1969, cuando se inició la creación de los espacios naturales protegidos. En el momento del crecimiento del turismo naturalista a partir de 1985, el sistema de áreas protegidas se constituyó en el soporte y base de la actividad turística.

Esta relación entre turismo y espacios protegidos y en especial la forma en que se realiza la promoción de la actividad turística hace que al turista se le califique como ecoturista, 
aunque el mismo turista en las encuestas realizadas por el ICT (2005) le es difícil ubicarse en tal categoría y menciona por el contrario su atracción y sensibilidad por la naturaleza.

Lo más importante es que el sector turismo que en un inicio utilizaba los espacios protegidos no prestaba atención a los impactos producidos por la actividad, pero en la actualidad gran parte de pequeños y grandes empresarios han adquirido conciencia ambiental y responsabilidad social, adoptando prácticas en armonía con la naturaleza que tienen como meta la conservación del recurso natural asociado.

Entre las iniciativas del sector turismo a la conservación están la certificación para la sostenibilidad turística, la integración del
Sistema Nacional de Áreas de Conservación (SINAC) a las políticas turísticas, el "Programa de Bandera Azul Ecológica”, la creación de reservas privadas y la integración de las comunidades rurales campesinas a la actividad turística como pequeños empresarios.

La certificación para la sostenibilidad turística es el proceso de evaluación de una unidad de servicio, en este caso turística, en función de un conjunto de criterios preestablecidos que buscan recompensar aquellos servicios turísticos que se desarrollan bajo prácticas eficientes. Para lograr la certificación, todo proyecto debe cumplir con criterios socio-culturales, económicos y ecológicos (Cuadro 4).

\section{CUADRO 4 \\ CRITERIOS PARA CUMPLIR CON LA CERTIFICACIÓN DE SOSTENIBILIDAD TURÍSTICA}

\begin{tabular}{ll}
\hline CRITERIOS & (1)Planificación ambiental y una evaluación de impacto que valore las incidencias en lo social, \\
GENERALES & lo cultural, lo ecológico y lo económico. (2) Compromiso con la gestión ambiental por parte \\
& del comercio en turismo. (3) Entrenamiento para el personal en educación, responsabilidad, \\
& conocimiento y conciencia de la gestión ambiental, social y cultural. (4) Mecanismos para \\
& monitorear e informar sobre el desempeño ambiental. (5) Mercadeo preciso y responsable que \\
conduzca a la formación de expectativas realistas.
\end{tabular}

CRITERIOS SOCIO (1) Impactos en las estructuras sociales, culturales y económicas (tanto local como CULTURALES nacionalmente). (2) Los procesos de adquisición y acceso de terrenos y de tenencia de la tierra llevados a cabo en forma apropiada. (3) Medidas para proteger la integridad de la estructura social de la comunidad. (4) Mecanismos para garantizar los derechos y aspiraciones de la población local e indígena.

CRITERIOS (1) Requerimientos para la práctica ética en los negocios. (2) Mecanismos para asegurar ECONÓMICOS que los arreglos laborales y los procedimientos en las relaciones industriales no exploten a los trabajadores y que, además, funcionen de acuerdo con las leyes locales y los estándares internacionales laborales (cualesquiera sean los más estrictos). (3) Mecanismos para asegurar que los impactos económicos negativos en las comunidades locales sean minimizados y que existan, preferiblemente, beneficios económicos sustanciales para las comunidades locales. (4) Requerimientos para garantizar contribuciones al desarrollo y mantenimiento de la infraestructura de la comunidad local.

$\begin{array}{ll}\text { CRITERIOS } & \text { (1) Ubicación adecuada de los sitios turísticos. (2) Conservación de la biodiversidad e integridad } \\ \text { ECOLÓGICOS } & \text { de los procesos del ecosistema. (3) Disminución de la perturbación del sitio, paisajismo } \\ & y \text { rehabilitación. (4) Drenaje, manejo de suelos y aguas pluviales. (5) Sostenibilidad en el } \\ & \text { suministro de energía y minimización de su uso. (6) Sostenibilidad en el suministro de } \\ & \text { agua y minimización de su uso. (7) Sostenibilidad en tratamiento y disposición de las aguas } \\ & \text { residuales. (8) Ruido y calidad del aire (incluyendo emisiones asociadas al efecto invernadero). } \\ & \text { (9) Minimización de desechos y sostenibilidad en su eliminación. (10) Impactos visuales } \\ & \text { y de luminosidad. (11) Sostenibilidad de materiales y suministros (materiales reciclados y } \\ & \text { reciclables, producidos localmente, productos madereros certificados, etcétera). (12) Impactos } \\ & \text { ambientales mínimos de las actividades. }\end{array}$

Fuente: Sanabria, R. 2001. “Acreditación a certificadores de turismo sostenible”. Revista Ambientico 98. p.17. 
El SINAC considera dentro de su gestión el promover, facilitar y participar en el desarrollo de un turismo sostenible en las áreas silvestres protegidas, basado en prácticas responsables de administración, planificación y manejo; además considerando la toma de decisiones, criterios acordes con las políticas de conservación de los recursos naturales y culturales (SINAC, 2006).

El "Programa de Bandera Azul Ecológica" se estableció como un incentivo a los hoteleros, cámaras de turismo y comunidades costeras para proteger, en forma integral, las playas de Costa Rica. El programa es dirigido y ejecutado por el Instituto Costarricense de Acueductos y Alcantarillados (AyA) que evalúa periódicamente la calidad del agua de las playas, con el fin de hacer diagnósticos sanitarios y proteger la salud de los visitantes a las zonas costeras. El AyA realiza anualmente un sistema de evaluación que sirve como incentivo para el cuidado de las playas, el cual consiste en otorgar la "Bandera Azul Ecológica" a la comunidad que logra satisfacer los aspectos de calidad del agua de mar, calidad de las playas, acceso a agua potable, tratamiento de las aguas residuales, educación ambiental, seguridad y administración (Cuadro 5).

CUADRO 5

COMUNIDADES Y PLAYAS CON BANDERA AZUL ECOLÓGICA AL AÑO 2008

\begin{tabular}{ll}
\hline PROVINCIA & \multicolumn{1}{c}{ POBLACIONES Y PLAYAS } \\
\hline GUANACASTE & $\begin{array}{l}\text { Bahía Junquillal, Manzanillo, Monte del Barco, Arenilla, Panamá, Buena, Hermosa, Ocotal, } \\
\text { Pan de azúcar, Flamingo, Conchal, Ventanas, Grande, Puerto El Maduro, Langosta, Bonita, } \\
\text { Mansita, Avellanas, Junquillal, Ostional, Pelada, Guiones, Camaronal, Punta islita. }\end{array}$ \\
\hline PUNTARENAS & Santa Teresa, El Carmen, Mal País, Quetzales, Pochote, isla Tortuga, Puntarenas, el Roble, \\
& Agujas, Limoncito, Mantas, Blanca, Bejuco, Dulce vida, Espadilla sur, Manuel Antonio, \\
& Gemelas, Puerto Escondido, Barú, Dominical, Ballena, Piñuela, Agujas, Blanca (Jiménez). \\
\hline LIMÓN & Negra (Cahuita), Blanca (Cahuita), Puerto Vargas, Negra (Puerto Viejo), Cocles, Chiquite, \\
& Punta Uva, Ned Creek, Gandoca Manzanillo. \\
\hline
\end{tabular}

Fuente: Acueductos y Alcantarillados. Estudios Básicos. 2008.

Nota: Las playas y comunidades que no están en letra cursiva tienen una categoría A, con calidad de agua de playa satisfactoria, playas sin contaminación sólida o líquida, agua potable, tratamiento de aguas residuales, basureros, educación ambiental y seguridad. Las que están en letra cursiva tienen además de lo anterior vigilancia, señalización de corrientes marinas, vigilancia en temporada alta.

Las reservas privadas van en aumento $y$ por lo general se dedican al turismo, pero siempre bajo la tutela y administración del SINAC. La conservación de la biodiversidad tiene un gran aliado en la iniciativa privada. A partir de 1990 los propietarios privados han establecidos formal o informalmente algún tipo de mecanismo mediante el cual protegen los recursos que existen en sus propiedades $y$ al mismo tiempo aprovechan los ingresos brutos generados por la actividad turística. Así varias de las fincas dedicadas a la conservación que se encuentran en manos privadas en sus diversas manifestaciones, se sostienen en gran parte por la generación de recursos provenientes del turismo, ejemplos son Rara Avis, Selva Verde, Tirimbina y Selva Tica en Sarapiquí.

Hasta mediados de la década de 1990, el turismo en Costa Rica estuvo en manos de grandes y medianos empresarios, la mayoría de capital externo y con desarrollo endógeno, donde no se tomaba en consideración a las comunidades locales campesinas, excepto por la demanda de algunos empleos y la venta esporádica de algunos productos agrícolas o artesanales.

Actualmente un importante grupo de cooperativas, asociaciones comunales y campesinos individuales han incursionado en el turismo como empresa que les brinda un complemento 
a sus actividades agropecuarias tradicionales. Es un turismo con gran participación y beneficio comunal, es decir una nueva forma de hacer turismo que muestra las costumbres rurales, su vida, tradiciones, cultura y respeto a la naturaleza. Es el turismo que Budowski (1990) denomino "turismo a la tica".

La participación campesina como pequeños empresarios del turismo se ha llevado a cabo mediante el apoyo del "Programa de Pequeñas Donaciones", del Fondo para el Medio Ambiente Mundial (FMAM) de las Naciones Unidas. En nuestro país la Asociación Costarricense de Turismo Rural Comunitario reúne a más de 80 asociados dedicados al turismo rural comunitario. Tiene una base completamente comunal porque la actividad turística es planificada e implementada por la misma organización comunitaria, por medio de la participación de los residentes presentes en su gestión y desarrollo, y obteniendo un máximo de beneficios (Mata, 1995).

El "Programa de Pequeñas Donaciones" (PPD) de las Naciones Unidas desde sus inicios en 1992 hasta la fecha, ha financiado en Costa Rica más de 400 proyectos a las ONG y organizaciones de base comunitaria, con una alta participación de mujeres e indígenas, poniendo a su disposición recursos para desarrollar acciones ambientales locales con incidencia global, especialmente en las áreas de turismo rural comunitario, agricultura orgánica y en territorios indígenas (Programa de Pequeñas Donaciones (PPD), 2007).

\section{CARACTERIZACIÓN DEL TURISMO NACIONAL Y EXTRANJERO EN LAS ÁREAS PROTEGIDAS}

El turismo nacional no tiene un comportamiento definido con respecto a las visitas a áreas silvestres protegidas, es muy irregular y fluctuante en su proceder, mientras que el turismo extranjero aumentó entre 1990 y 1994 en casi un $100 \%$, luego desciende en un 33\% en 1995 y tarda cinco años en reponerse de esta caída. Esta disminución fue originada por el aumento en las tarifas de entrada a las áreas protegidas, aunque a partir del 2002 aumenta $y$ se recupera (Cuadro 6).

CUADRO 6

NÚMERO DE EXTRANJEROS Y NACIONALES QUE VISITAN ÁREAS PROTEGIDAS 1990-2005

\begin{tabular}{|c|c|c|c|c|c|}
\hline AÑO & $\begin{array}{l}\text { VISITANTES } \\
\text { NACIONALES }\end{array}$ & PORCENTAJE & $\begin{array}{c}\text { VISITANTES } \\
\text { EXTRANJEROS }\end{array}$ & PORCENTAJE & TOTAL \\
\hline 1990 & 304642 & 59,00 & 206591 & 40,41 & 511233 \\
\hline 1991 & 226655 & 46,04 & 265679 & 53,96 & 492334 \\
\hline 1992 & 255322 & 44,03 & 324495 & 55,97 & 579817 \\
\hline 1993 & 367683 & 47,62 & 404342 & 52,38 & 772025 \\
\hline 1994 & 322148 & 45,99 & 378286 & 54,01 & 700434 \\
\hline 1995 & 362341 & 59,00 & 251740 & 41,00 & 614081 \\
\hline 1996 & 389883 & 59,19 & 268774 & 48,81 & 658657 \\
\hline 1997 & 452680 & 60,94 & 290081 & 39,06 & 742761 \\
\hline 1998 & 485950 & 59,99 & 324148 & 40,01 & 810098 \\
\hline 1999 & 495829 & 57,25 & 370254 & 42,75 & 866083 \\
\hline 2000 & 471528 & 58,06 & 340574 & 41,94 & 812102 \\
\hline 2001 & 478838 & 55,66 & 381373 & 44,34 & 860211 \\
\hline 2002 & 507801 & 55,22 & 411831 & 44,78 & 919632 \\
\hline 2003 & 463602 & 46,62 & 530777 & 53,38 & 994379 \\
\hline 2004 & 476633 & 44,81 & 586959 & 55,19 & 1063592 \\
\hline 2005 & 455487 & 42,60 & 611334 & 57,40 & 1066821 \\
\hline
\end{tabular}

Fuente: SINAC. Áreas silvestres protegidas. 2006. 
DeShazo y Monestel (1999, 1999a, 1999b y 1999c) realizan una excelente caracterización de los turistas extranjeros y nacionales que visitan las áreas protegidas públicas de Costa Rica, estudios que tomaremos como base para este análisis.
Los turistas extranjeros visitan en promedio 4,5 áreas públicas protegidas durante la estadía en nuestro país. La estadía promedio es de 16,1 días de los cuales 10,6 los dedican a visitas a espacios protegidos, es decir el 65,83 \% de su tiempo (Cuadro 7).

CUADRO 7

COMPORTAMIENTO DEL TURISMO EXTRANJERO EN ÁREAS PROTEGIDAS

\begin{tabular}{lcccc}
\hline REGIÓN & $\begin{array}{c}\text { NÚMERO PROMEDIO } \\
\text { DE LUGARES } \\
\text { VISITADOS }\end{array}$ & $\begin{array}{c}\text { ESTADÍA PROMEDIO } \\
\text { DE DÍAS }\end{array}$ & $\begin{array}{c}\text { TIEMPO TOTAL } \\
\text { DEDICADO A LAS } \\
\text { ÁREAS PROTEGIDAS }\end{array}$ & $\begin{array}{c}\text { \% DE TIEMPO } \\
\text { DEDICADO A LAS }\end{array}$ \\
\hline América del Norte & 4,3 & 14,3 & 10,0 & 70,0 \\
América del Sur & 5,1 & 15,3 & 9,3 & 61,0 \\
Europa & 5,2 & 20,9 & 12,3 & 58,7 \\
Asia & 4,6 & 14,0 & 12,3 & 87,4 \\
Oceanía & 4,8 & 19,4 & 13,4 & 69,2 \\
A. Central y el Caribe & 3,0 & 12,7 & 6,6 & 52,0 \\
\hline
\end{tabular}

Fuente: Encuesta de áreas protegidas de Costa Rica. Harvard Institute for Internacional Development. INCAE. 1999.

El cuadro 7 nos muestra que los europeos son los que visitan el mayor número de lugares con 5,2 días y con 20,9 días de estadía en el país, pero los asiáticos y norteamericanos a pesar de estar un día menos en el país dedican mayor cantidad de tiempo a la visita de áreas protegidas.

Así tenemos, que mientras los europeos invierten un $58,7 \%$ de su tiempo en visitas a espacios protegidos, los asiáticos lo hacen en un $87,4 \%$ que es muy elevado y los norteamericanos son segundos con un $70 \%$. Esto se explica por una mayor inclinación de los europeos a visitar hoteles de playa (DeShazo y Monestel, 1999b).

Los centroamericanos y caribeños son los que están menos días en el país y asisten en menor número de días a las áreas naturales, lo cual puede ser originado por dos causas: primero, que ellos al encontrarse en la misma zona tropical asistan en sus países a atractivos equivalentes y segundo, que la situación económica que disponen es menos solvente. Por el contrario, los turistas de la región templada sienten mayor atracción por los paisajes tropicales que les parecen atrayentes, excepcionales y exóticos por su gran diversidad y riqueza.

Al relacionar la duración con la estadía, el largo de la estadía declina con la edad, siendo de 20,1 días para visitantes de 24 años y de 12 días para visitantes de 61 años y más, lo que se explica no solo por la edad, sino también por condiciones de salud de las personas adultas mayores. A nivel de género, no existe una diferencia significativa entre los hombres y las mujeres en la duración de la estadía, llegando la diferencia a apenas 1,5 días (DeShazo y Monestel, 1999).

Los turistas locales realizan un promedio de 5,8 viajes al año a áreas protegidas públicas, aunque muestran un mayor ingreso durante los periodos de vacaciones escolares en diciembre, enero, febrero y julio.

Las personas con ingresos superiores a los 1300 dólares mensuales hacen hasta 5,7 viajes al año, mientras que para las personas con salarios inferiores, el número de visitas es menor a 3,7 viajes al año. Para los costarricenses influyen los elevados costos en el traslado, hospedaje y comida que finalmente para una 
familia de cuatro miembros resulta en 183 dólares por día, que equivale a más de un salario base.

La visita a un área protegida crea un estímulo para el consumo de servicios de alimentación, hospedaje, transporte o pagos de visitas programadas dentro o fuera del lugar de ubicación área silvestre. Los que reciben el mayor beneficio en forma directa son los establecimientos y empresas ubicadas en las cercanías del lugar, como es el caso de los alrededores del volcán Poás, Monteverde, Manuel Antonio, volcán Irazú. Cuando la visita se realiza en dos o tres áreas protegidas en un mismo día los lugares de servicios o de estadía intermedios se ven igualmente beneficiados.

La estadía del turista extranjero en el país está comprendida entre los 12 y 21 días, con lo que el gasto promedio es de 2224 dólares; si se supone que los turistas utilizan el $60 \%$ de su tiempo en visitar áreas protegidas se tiene entonces que de esos 2224 dólares, la cantidad de 1334 está relacionada con la visita a alguna área protegida (DeShazo y Monestel, 1999a).

El ingreso que produce el visitante extranjero y nacional en las áreas protegidas es 37426333 dólares al año, de este total el $62,94 \%$ proviene de extranjeros y el $37,05 \%$ de nacionales, siendo el parque nacional Manuel Antonio el que produce mayores ingresos con más de 11 millones de dólares, seguido por los parques nacionales volcán Poás e Irazú (Cuadro 8), que son los que presentan mejores caminos de acceso y mayor cercanía a la capital y al aeropuerto Juan Santamaría.

CUADRO 8

GASTOS ANUALES DE LOS TURISTAS NACIONALES Y EXTRANJEROS EN LAS ÁREAS PROTEGIDAS

\begin{tabular}{cccc}
\hline LUGAR & GASTO DE EXTRANJEROS & GASTOS DE NACIONALES & GASTO TOTAL \\
\hline Manuel Antonio & 8423868 & 3392767 & 11816635 \\
Poás & 4997293 & 2304056 & 7301350 \\
Irazú & 1969133 & 1979678 & 3948811 \\
Santa Rosa & 1199088 & 2136542 & 3335631 \\
Corcovado & 2825505 & 406018 & 3231524 \\
Arenal & 1200576 & 1624484 & 2825160 \\
Rincón de la Vieja & 1704348 & 519429 & 2223777 \\
Cahuita & 213076 & 824477 & 1037553 \\
Cabo Blanco & 746590 & 125140 & 871730 \\
Guayabo & 193354 & 397467 & 590821 \\
Tapantí & 83534 & 159810 & 243344 \\
TOTAL & 23556365 & 13869968 & 37426333 \\
\hline
\end{tabular}

Fuente: DeShazo y Monestel, 1999a.

Las actividades más importantes para los turistas extranjeros son en su orden observar volcanes, caminar en senderos, observar aves y otros animales, nadar y tomar el sol (Cuadro 9). 
CUADRO 9

ACTIVIDADES A REALIZAR POR LOS TURISTAS SEGÚN REGIÓN DE PROCEDENCIA EN PORCENTAJES

\begin{tabular}{cccccc}
\hline ACTIVIDAD & $\begin{array}{c}\text { AMÉRICA DEL } \\
\text { NORTE }\end{array}$ & $\begin{array}{c}\text { AMÉRICA DEL } \\
\text { SUR }\end{array}$ & EUROPA & ASIA & CENTROAMÉRICA \\
\hline Caminar en senderos & 84,8 & 80,0 & 84,9 & 70,6 & 75 \\
Caminatas rigurosas & 45,0 & 75,6 & 49,1 & 47,0 & 65 \\
Nadar o tomar sol & 75,7 & 81,7 & 72,7 & 88,2 & 30 \\
Observar aves y otros & 87,8 & 80,0 & 87,4 & 81,8 & 50 \\
animales & 33,6 & 34,8 & 30,7 & 41,2 & 20 \\
Rafting & 31,1 & 33,0 & 29,0 & 41,2 & 15 \\
Pesca deportiva o buceo & 17,5 & 21,7 & 16,8 & 17,6 & 10 \\
Surf & 76,9 & 80,9 & 81,5 & 70,6 & 90 \\
Observar volcanes & 39,7 & 40,9 & 39,9 & 52,9 & 40 \\
Picnic & & & & & \\
\hline
\end{tabular}

Fuente: Encuesta de áreas protegidas, Costa Rica. Harvard Institute for Internacional Development. INCAE. 1999.

La actividad preferida del turista extranjero con excepción del centroamericano es la observación de aves y otros animales; quizá el poco interés de los centroamericanos (50\%) hacia esta actividad se debe a la similitud existente entre los países del istmo; mientras que las actividades menos practicadas son el surf y la pesca deportiva. El turista costarricense tiene como actividades predilectas la caminata rigurosa $(67,2 \%)$, caminar en senderos $(67 \%)$, picnics $(64,9 \%)$ y la observación de aves y otros animales (63,4\%), lo del picnic constituye una posibilidad muy importante porque se realiza en un día y esto le permite reducir los costo de la visita (DeShazo y Monestel, 1999c).

La calidad de los servicios recibidos por los turistas es muy importante porque de ella depende la satisfacción plena y la recomendación a otras personas, con lo cual se crea una excelente imagen del país y su naturaleza.

No es sorprendente que los caminos de acceso a las áreas protegidas sean los que originaron la mayor inconformidad $y$ disgusto (Cuadro 10); otro rubro importante de insatisfacción es la calidad de los servicios sanitarios y la disponibilidad de información; este último aspecto, es citado por los europeos y asiáticos, lo que es comprensible por la brecha del idioma. Un bajo porcentaje (11\%), en especial europeos y asiáticos consideran que la poca existencia de hoteles y restaurantes cercanos a los espacios protegidos es una limitación.

Lo más importante para nuestro país es que a excepción de la calidad de los caminos de acceso, en todos los rubros las calificaciones de excelentes superan a las de pobre en amplios porcentajes. Igualmente importante es que más del $85 \%$ de las personas considera oportuno recomendar un amigo, lo que muestra un grado de satisfacción muy alto y que se constituye en una forma de propaganda directa del país como destino de la naturaleza (Cuadros 10 y 11) (DeShazo y Monestel, 1999b). 


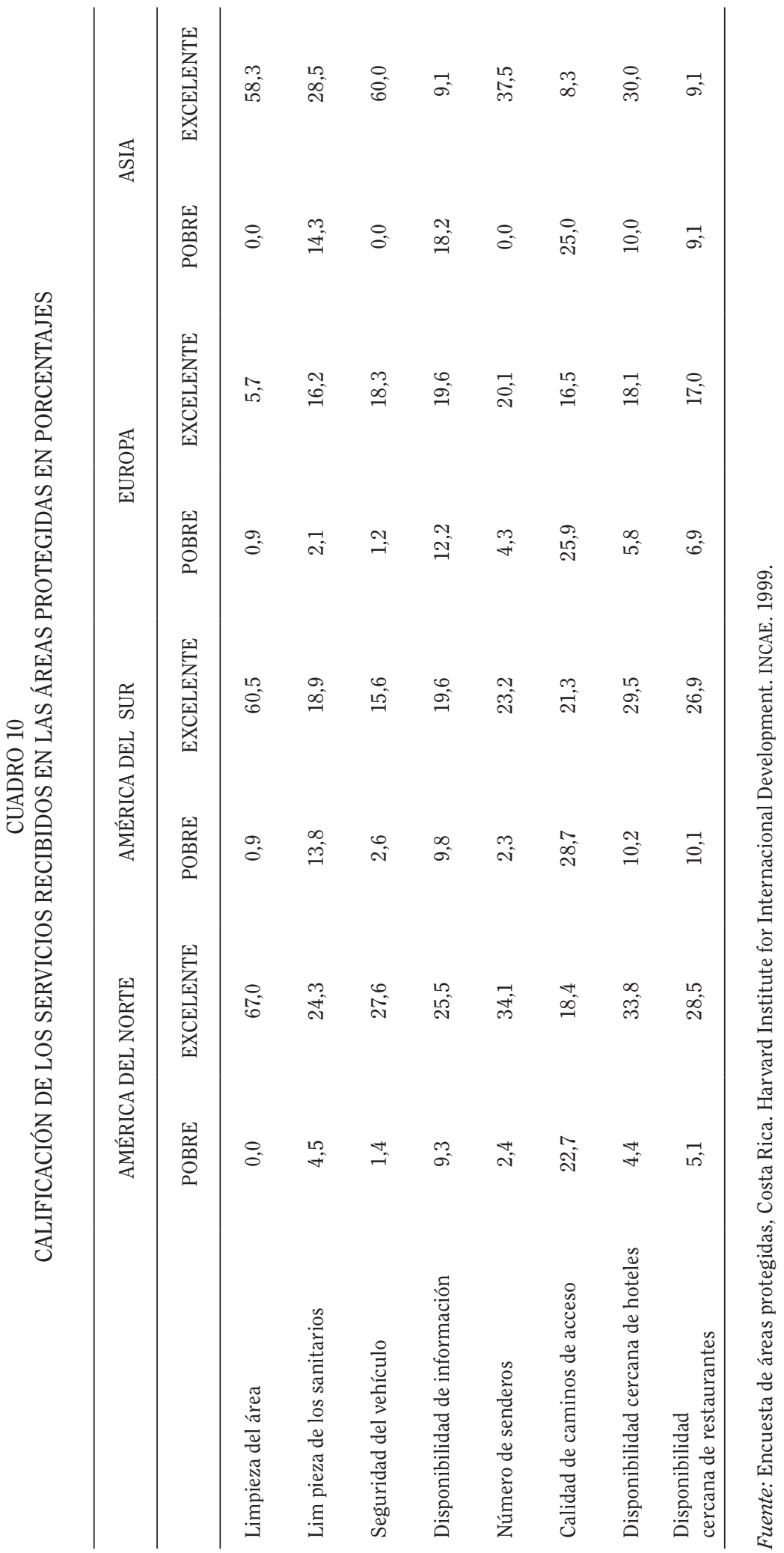


CUADRO 11

PORCENTAJE DE RECOMENDACIÓN DE LAS VISITAS A ÁREAS PROTEGIDAS A AMISTADES

\begin{tabular}{lccccccccc}
\hline & \multicolumn{2}{c}{$\begin{array}{c}\text { AMÉRICA DEL } \\
\text { NORTE }\end{array}$} & \multicolumn{2}{c}{$\begin{array}{c}\text { AMÉRICA DEL } \\
\text { SUR }\end{array}$} & \multicolumn{2}{c}{ EUROPA } & \multicolumn{2}{c}{ ASIA } \\
\hline & NO & SÍ & NO & SÍ & NO & Sí & NO & SÍ \\
\hline $\begin{array}{l}\text { Recomendaría los lugares } \\
\text { visitados }\end{array}$ & 0,4 & 86,4 & 0,0 & 92,6 & 0,5 & 84,6 & 0,0 & 83,3 \\
\hline
\end{tabular}

Fuente: Encuesta de áreas protegidas, Costa Rica. Harvard Institute for Internacional Development. INCAE. 1999.

La forma en que conocieron previamente estos lugares fue por medio de libros de turismo $y$ sitios web (43,55\%), por familiares y amigos $(39,12 \%)$, por agencias de viajes $(13,42 \%)$ y por otros medios (3,91\%) (DeShazo y Monestel, 1999c). Esta información es muy importante porque la promoción efectiva depende de la capacidad del medio para servir de vehículo de información hacia el destinatario final, que es el turista potencial. El segundo medio de promoción más importante es el contacto directo de amigos $y$ familiares por eso se deben corregir las limitaciones como los malos caminos de acceso hacia las áreas protegidas, contar con servicios sanitarios accesibles, cómodos y siempre limpios, ya que este aspecto es uno de los más criticados.

Cada área protegida debe contar con un presupuesto suficiente para cumplir en primer lugar, con las funciones de conservación e investigación y en segundo lugar, para hacer frente a las exigencias que demanda el turista.

La Ley de Biodiversidad de 1998, en su artículo 36 autorizaba al SINAC administrar los fondos que entran al sistema por cualquier concepto y el artículo 38, establece que el SINAC utilizará en las áreas de conservación, para su funcionamiento, la totalidad de los fondos que generen sus actividades, tales como las tarifas de ingreso a las áreas protegidas o las concesiones de servicios no esenciales, que serán administrados por medio de un fideicomiso de áreas protegidas.

Los fondos que generen las áreas protegidas serán exclusivamente para su protección $y$ desarrollo, en ese orden de prioridad; sin embargo, el dinero que generan va, una parte, a la caja única del Estado y la otra, al Ministerio del Ambiente y Energía (MINAE) para cubrir gastos no relacionados al sistema y a los parques nacionales, como es el pago de salarios a los burócratas.

Dos ejemplos concretos del funcionamiento real son los parques nacionales Tortuguero y Manuel Antonio. En el año 2003 el parque nacional Tortuguero generó 100 millones de colones, pero únicamente recibió para su presupuesto anual 2,5 millones de colones, cifra insuficiente para ejercer un adecuado control $y$ vigilancia de los recursos naturales del parque en sus 76000 ha. Un caso similar al descrito es el del parque nacional Manuel Antonio, el segundo parque más visitado; en el año 2005 generó aproximadamente 325 millones de colones (650 000 dólares), sin embargo le devolvieron de 5 a 8 millones de colones (10 000 a 16000 dólares) para operación (Fürst, Moreno, García y Zamora, 2004). Bajo estas condiciones las diferentes áreas de manejo tienen grandes problemas de financiamiento que les impiden, contar con dinero hasta para las actividades más esenciales $y$ de bajo costo, como es el caso de las rondas forestales para evitar que se pasen los incendios o para mantener los servicios sanitarios limpios, con jabón y papel higiénico.

\section{HACIA UN TURISMO RESPONSABLE}

El ser responsable conlleva en primer lugar un cumplimiento de obligaciones adquiridas por acciones o cosas realizadas y en segundo lugar poner atención o cuidado a lo que se hace, por lo tanto, la responsabilidad se traduce en la obligación y compromiso de quién ejecuta 
la acción de reparar cualquier daño causado o cumplir con las acciones propuestas y que estas no estén en desacuerdo a normas ambientales y sociales existentes. De esta manera, la responsabilidad no es nada nuevo, ha existido desde siempre, sin embargo la hacen parecer algo nuevo y que nace ligada al concepto de sostenibilidad y a las políticas de desarrollo sostenible.

El concepto de desarrollo sostenible constituye el eje fundamental en el análisis y en la política de la ONU en materia de desarrollo $y$ medio ambiente. Dos hechos importantes marcan la dirección en la evolución del concepto de desarrollo sostenible: primero, la publicación en 1987 del informe Brundtland, por la Comisión Mundial del Medio Ambiente y el Desarrollo y segundo, la Conferencia de las Naciones Unidas para el Medio Ambiente y el Desarrollo celebrada, en Río de Janeiro en 1992.

El concepto de desarrollo sostenible no se refiere a un estado estable, fijo, de armonía, sino a situaciones de cambio, enfatizando el carácter dinámico del desarrollo y reconoce la existencia de conflictos y desequilibrios que son el reflejo de situaciones cambiantes dinámicas (Bifani, 1997).

En el enfoque de desarrollo sostenible se distinguen al menos dos puntos de vista importantes. Uno enfatiza los límites ecológicos y la importancia de crecimiento continuo en un planeta finito. El otro resalta la solidaridad con las generaciones futuras y por lo tanto, la necesidad de preservar los recursos naturales $y$ ambientales de modo que dichas generaciones dispongan de un máximo de opciones para maximizar su bienestar. Se argumentó que la generación presente tiene la responsabilidad moral de salvaguardar el capital natural para las futuras generaciones (Harribey, 1998).

En la Cumbre de la Tierra de Río de Janeiro, el desarrollo sostenible es el eje fundamental para toda estrategia económica, y por lo tanto, del turismo, por esta razón surge mucha información y aportes en los ámbitos político, científico y empresarial en relación con el turismo y la sostenibilidad.

Un año después de Río, la Organización Mundial de Turismo (OMT, 1993) definió el concepto de Turismo Sostenible, como aquel turis- mo que atiende a las necesidades de los turistas actuales $y$ de las regiones receptoras y al mismo tiempo protege $y$ fomenta las oportunidades para el futuro. Se concibe como una vía hacia la gestión de todos los recursos de forma que puedan satisfacerse las necesidades económicas, sociales y estéticas, respetando al mismo tiempo la integridad cultural, los procesos ecológicos esenciales, la diversidad biológica y los sistemas que sostienen la vida.

En 1994, la Organización Mundial del Turismo considera fundamentales para la implantación de la Agenda 21 en los centros turísticos, los siguientes requisitos: minimización de los residuos; conservación y gestión de la energía, gestión del recurso agua, control de las sustancias peligrosas, planeamiento urbanístico y gestión del suelo, compromiso medioambiental de los políticos y de los ciudadanos, diseño de programas para la sostenibilidad y colaboración para el desarrollo turístico sostenible (López, 2001).

La Carta Mundial del Turismo Sostenible de 1995 establece 18 principios que tratan de poner los fundamentos para una estrategia turística mundial basada en el desarrollo sostenible (López, 2001) y en 1999 se establece el Código Ético Mundial del Turismo (Organización Mundial del Turismo, 1999).

El artículo 3, del Código Ético (Organización Mundial del Turismo, 1999) establece que todos los agentes del desarrollo turístico tienen el deber de salvaguardar el medio ambiente y los recursos naturales, en la perspectiva de un crecimiento económico saneado, constante y sostenible, que sea capaz de satisfacer equitativamente las necesidades $y$ aspiraciones de las generaciones presentes $y$ futuras, $y$ se reconoce al turismo de naturaleza $y$ el ecoturismo como formas de turismo particularmente enriquecedoras $y$ valorizadoras, siempre que respeten el patrimonio natural y la población local y se ajusten a la capacidad de ocupación de los lugares turísticos.

El turismo sostenible no hace referencia a ninguna forma de turismo específica, aunque parece que el turismo tradicional tiene más dificultad en alcanzar la sostenibilidad, ya que su práctica en las unidades turísticas está 
diseñada para separar a los turistas de los contextos naturales, sociales, culturales y económicos del sitio que visitan. En el contexto natural el ambiente es construido y no real como playas blancas con largas filas de cocoteros, hoteles con lagos $y$ cascadas $y$ no se es conciente del grado de contaminación generada por los hoteles. En el aspecto social no hay ninguna interrelación con la comunidad y población local, siendo la única relación que se tiene la de cliente empleado.

El turismo alternativo se acerca más a la sostenibilidad, no obstante bajo el término turismo alternativo se agrupan diversas formas turísticas, algunas de las cuales son gestionadas con un espíritu de lucro similar a las tradicionales y con impactos más que dudosos. Fennell (1999) y Money (1999) identifican los principios del turismo responsable o sostenible, ocho de ellos son: contribuye a la conservación, fortalece y crea beneficios a las comunidades locales, es de bajo impacto, de pequeña escala, promueve una conciencia ecológica, provee beneficios financieros directos a la conservación, respeta la cultura local y apoya los derechos humanos y los movimientos democráticos.

El turismo responsable puede entonces definirse como un viaje que toma en consideración los contextos naturales, socio-culturales, económicos y políticos de un destino en la búsqueda por aumentar los beneficios y minimizar los impactos negativos del turismo.

\section{LA CAPACIDAD DE CARGA COMO UN MEDIO DE CONTROL DE IMPACTOS}

El turismo está lejos de ser una actividad "blanca" o "suave", por el contrario, es causante de impactos directos e indirectos en todos los sectores de la economía y muchos más impactos imprevisibles en la cultura y costumbres de un pueblo. Sea cuál sea su modalidad o el nombre que le designemos ecoturismo, turismo verde, turismo sostenible, turismo ambiental, es una actividad que requiere preparación, visión y disciplina para evaluar su función en la sociedad. Análisis ligeros, fundamentados apenas en números de empleos, rentabilidad de los negocios e incremento en el PIB nacional o local son una superficialidad.
Los espacios naturales protegidos en sus diversas categorías de manejo son considerados como una de las mejores alternativas para la conservación de la biodiversidad de especies, de ecosistemas ya que constituyen muestras representativas de la diversidad natural del país y sus unidades ecológicas. En estas áreas se protege con carácter intangible la integridad ecológica de los ecosistemas, los procesos sucesionales y evolutivos, así como otras características estéticas paisajísticas y culturales.

La intangibilidad no implica que no pueda realizarse intervenciones, por lo que se permite el ingreso de visitantes con fines científicos, educativos, recreativos y culturales. Por otro lado, el turismo en áreas naturales con fines recreativos se ha constituido en una actividad económica importante, ya que en los últimos años se ha convertido en uno de los sectores más productivos; como es el caso particular de nuestro país, pero origina impactos de muy diversa índole, entre ellos impactos ecológicos y geomorfológicos (Butler, 1980).

En los impactos ecológicos sobresalen la disminución en la cantidad y diversidad de aves cerca de los senderos, disminución y alteración de los procesos de regeneración al ser destruidas las plántulas con el excesivo pisoteo de los visitantes fuera de los senderos, retiro de mamíferos hacia el interior a causa de ruidos continuos y modificación de los hábitos de alimentación en animales. Los impactos geomorfológicos se producen por el aumento en la erosión, en especial en los alrededores de los senderos.

El manejo de visitantes en un área protegida debe ser rigurosamente planificado para alcanzar los objetivos de conservación por los cuales fue creada $y$, a la vez, lograr que los visitantes tengan una experiencia de calidad $y$ puedan satisfacer sus expectativas. Para eso es importante establecer la capacidad de carga de visitación que los sitios destinados al uso público pueden soportar.

El concepto de capacidad de carga nació a inicios de 1970 como una aplicación en estudios de cría del ganado para establecer cuantitativamente la explotación potencial máxima de un sistema agropecuario y luego se utiliza en la ecología para definir la capacidad de carga de 
una población dada de una especie, mantenida indefinidamente en un habitat sin ocasionar daños en el ecosistema, para finalmente aplicarla a la visitación turística en espacios protegidos (Chaverri y Cerdas, 1999).

En relación con el turismo, el término implica el número de visitantes permitidos en los diferentes sitios como senderos naturales, áreas de acampar, caminos de comunicación entre un sitio y otro de un área silvestre, en un mismo periodo de tiempo, sin que esa presencia $y$ actividades ocasionen deterioro de los recursos naturales, culturales o de la infraestructura del sitio (Chaverri y Cerdas, 1999). (Fotos 5 y 6).

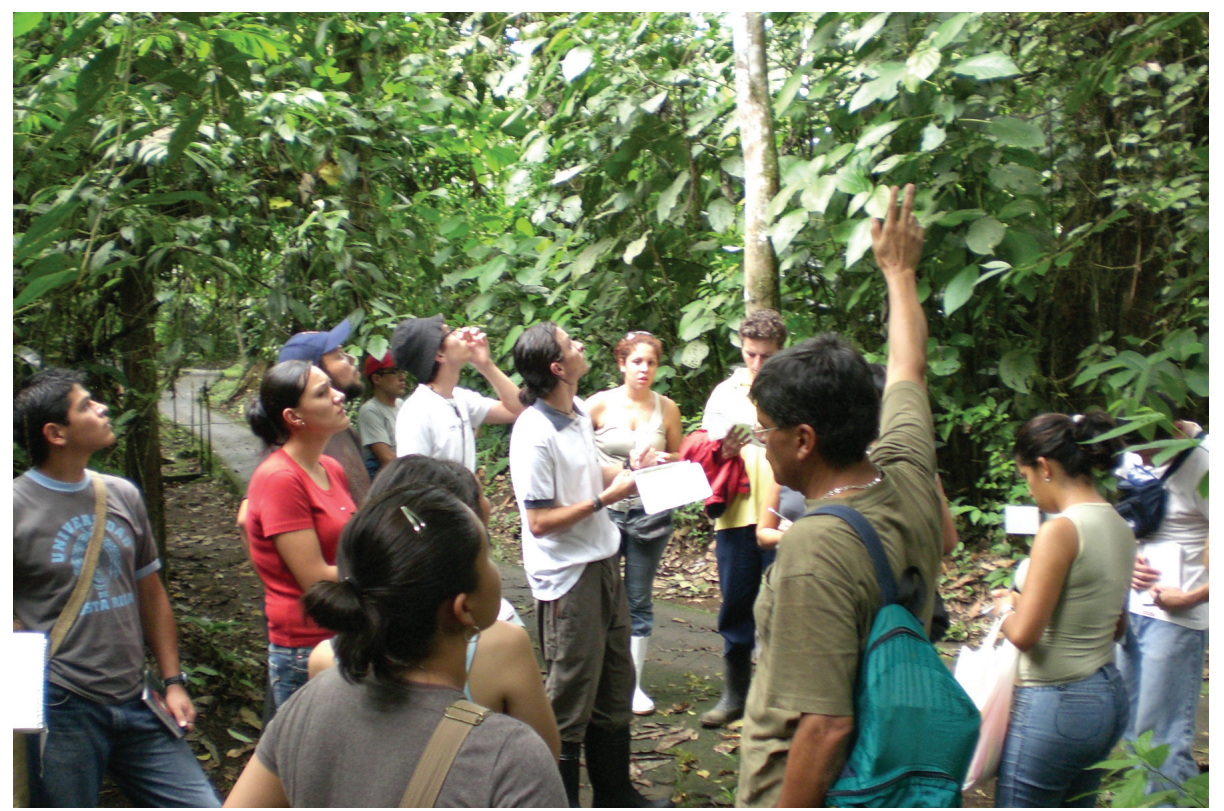

Foto 5. Grupos de personas fuera de los senderos ocasionan un impacto negativo en la regeneración de especies.

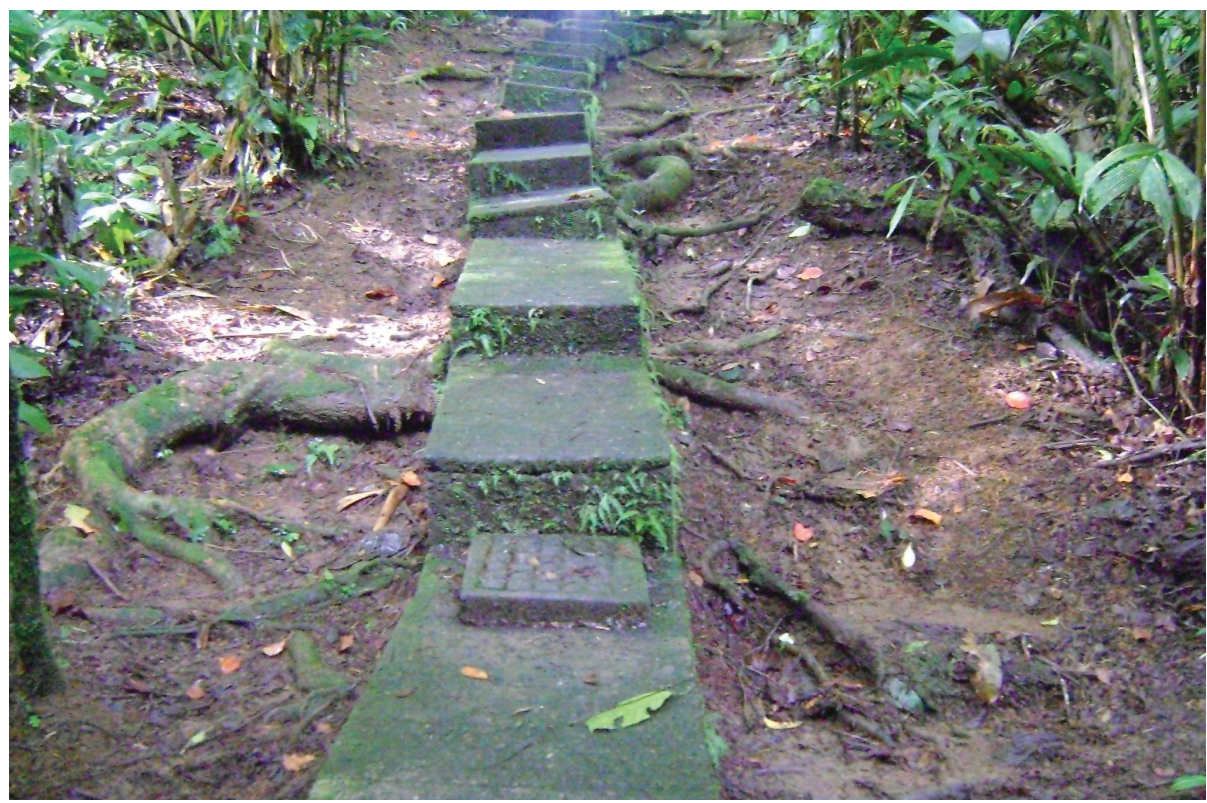

Foto 6. Fuerte erosión en senderos de cemento que ocasionan arrastre de gran cantidad de materia orgánica 
En Costa Rica la metodología de capacidad de carga más conocida es la realizada por Cifuentes, Alpízar, Barroso, Corrau, Falck y Ortiz (1990) empleada por primera vez en la reserva biológica de Carara, hoy parque nacional, la cual define tres tipos de capacidad de carga: la capacidad de carga física, la capacidad de carga real y la capacidad de carga efectiva (Cuadro 12). Las capacidades de carga se obtienen por medio de variables topográficas, climáticas, ecológicas $y$ de manejo.

CUADRO 12

VARIABLES UTILIZADAS EN LA METODOLOGÍA DE CAPACIDAD DE CARGA DE CIFUENTES Y COLABORADORES

\begin{tabular}{|c|c|c|}
\hline CAPACIDAD DE CARGA FÍSICA & CAPACIDAD DE CARGA REAL & CAPACIDAD DE CARGA EFECTIVA \\
\hline $\begin{array}{l}\text { Cantidad máxima de visitantes en un espacio } \\
\text { dado, en un periodo de tiempo deteminado. }\end{array}$ & $\begin{array}{l}\text { Capacidad de carga física } \\
\text { Variables ambientales } \\
\text { Lluvia } \\
\text { Inundaciones } \\
\text { Horas sol } \\
\text { Mareas } \\
\text { Niebla } \\
\text { Variables físicas } \\
\text { Erosión } \\
\text { Pendiente } \\
\text { Compactación } \\
\text { Variables ecológicas } \\
\text { Disturbios en flora y fauna } \\
\text { Variables de manejo } \\
\text { Horario al público } \\
\text { Cierres temporales } \\
\text { Tamaño del grupo } \\
\text { Distancia entre grupos } \\
\text { Duración en el sitio } \\
\text { Rutas escogidas } \\
\text { Preferencias turísticas }\end{array}$ & $\begin{array}{l}\text { Capacidad de carga real } \\
\text { Capacidad de gestión que depende } \\
\text { Personal } \\
\text { Equipo } \\
\text { Infraestructura } \\
\text { Financiamiento }\end{array}$ \\
\hline
\end{tabular}

Fuente: Chaverri y Cerdas, 1999.

La capacidad de carga en la mayoría de los espacios protegidos de Costa Rica se ha establecido por medio de decretos ejecutivos del MINAE y no se ha determinado por medio de la aplicación de metodologías serias y científicas; todo lo contrario, fueron definidas según la experiencia del personal de las áreas.
Una minoría de las áreas protegidas cuenta con estudios científicos, como las de Cifuentes, Alpízar, Barroso, Corrau, Falck y Ortiz (1990) para el Parque Nacional Carara, el de Brenes, Castro, Jiménez, Mejía y Mora (2004) para el parque internacional La Amistad, el de Cifuentes (1999) para el Monumento Nacional Guayabo y el de Abarca y Vega (1991) para la Reserva absoluta de Cabo Blanco (Cuadro 13). 
CUADRO 13

DETERMINACIÓN DE LA VISITACIÓN EN ÁREAS PROTEGIDAS DE COSTA RICA

\author{
ÁREA PROTEGIDA \\ CONTROL Y DETERMINACIÓN DE LA VISITACIÓN
}

Parque Nacional Tortuguero

Establecida por decreto 29628 de MINAE. Se determina una velocidad de $5 \mathrm{~km} /$ hora en el sendero acuático, grupos de 10 personas como máximo para observar el desove y grupos de 8 personas cada 15 minutos en los senderos continentales.

Parque Nacional Chirripó

Por decreto 32456 de MINAE: 40 personas por día. Se prohíbe el uso de caballos en senderos y cierra el parque un mes al año para labores de mantenimiento y para que la fauna pueda desplazarse en las partes altas.

Monumento Nacional Guayabo

404 personas por día como carga real. Cifuentes (1999).

Parque Nacional Carara

Sendero de la laguna Meándrica y sendero de aventura con grupos de 25 personas cada 15 minutos. Cifuentes, Alpízar, Barroso, Corrau, Falck y Ortiz (1990) y decreto MINAE nro. 32505.

Parque Internacional La Amistad

Sendero Kamuk 37 personas por día, sendero Cabecar 34 personas/día, sendero sabana esperanza 118 personas/día, sendero valle del silencio 14 personas/día y el sendero gigantes del bosque 47 personas/día. Brenes, Castro, Jiménez, Mejía y Mora (2004).

Reserva natural absoluta Cabo Blanco

Límite máximo de 90 personas por día en grupos de 15 personas, con distancias de 700 m entre cada grupo. Abarca y Vega (1991).

Parque Nacional Manuel Antonio

El límite máximo de visitación por día se fija en 600 en la semana y 800 en fines de semana. En grupos de 2 a 70 personas. No se controla distancia. Decreto MINAE 33409.

Reserva biológica bosque nuboso Monteverde

Establecido por el Centro Científico Tropical. Límite máximo de 125 visitantes por día en grupos de 9 a 12 personas, con tiempo entre grupos de 15 a 20 minutos (Chaverri y Cerdas, 1999).

Parque Nacional Volcán Poás

Límite dado por decreto y relacionado con la capacidad del parqueo. Alrededor de 3000 personas al día. La fuente Chaverri y Cerdas (1999) no citan número de decreto.

Parque Nacional Volcán Irazú L Límite máximo de 900 visitantes al día, dado por decreto. La fuente Chaverri y Cerdas (1999) no citan número de decreto.

Fuente: SINAC. 2007.

Gutiérrez (1999) considera que en nuestro país, ante el crecimiento del turismo en los espacios protegidos y la urgencia de tomar medidas de control se recurrió a los reglamentos de uso público para dotar a las áreas silvestres de mecanismos que permitieran disminuir el impacto del visitante y señala que estos reglamentos no se basan en el criterio de capacidad de carga, sino en el de capacidad de manejo $y$ control como mecanismos de reducción del impacto por visita. Para su cumplimiento, se establecieron instrumentos de control como la señalización de sitios de circulación restringida, entre ellos senderos, zonas donde los grupos no pueden exceder cierto tamaño, donde la cantidad de grupos no pueden sobrepasar cierto número y donde sólo se puede ingresar en un horario establecido. 


\section{CONCLUSIÓN}

Los ecosistemas tropicales son frágiles cuando padecen la intervención del ser humano y para su reconstrucción necesitan decenas de años e incluso centenas si la alteración es muy significativa.

Costa Rica ha desarrollado en América Central uno de los mejores sistemas de áreas protegidas y uno de los primeros en América Latina; estas áreas son el fundamento del turismo naturalista. La demanda creciente del turismo internacional $y$ nacional por los parques nacionales, reservas biológicas y otras categorías de manejo como atractivos turísticos ponen en peligro los procesos biológicos de migración, reproducción y de sucesión.

El establecer el número de visitantes por día por medio de reglamentos de uso público y de decretos ejecutivos es una decisión política que demuestra una gran falta de planificación; ya que, la única forma de establecerla en forma seria, es por medio del análisis de las características climáticas, edáficas, topográficas, bióticas $y$ de manejo de cada sendero en las áreas de uso público. Todo bajo un respaldo de datos ambientales y socioeconómicos registrados durante más de cinco años y lo más importante que la metodología aplicada haya sido verificada en países tropicales. De lo contrario, la protección de los recursos existentes en cada una de las áreas es inadecuada.

El no contar con un financiamiento adecuado para la contratación de guardaparques, no permite controlar en forma efectiva los grupos y sus distancias en tiempo y espacio, lo que provoca impactos negativos fuera de los senderos. Lo anterior, unido a la presión ejercida por empresarios de turismo en el aumento de la visitación en parques nacionales como Carara, Manuel Antonio, volcán Poás e Irazú puede ocasionar a mediano plazo daños ecológicos irreversibles, lo único positivo es que este impacto se realiza en las áreas de uso público y estas comprenden únicamente entre el $0,02 \%$ y $0,15 \%$ de la superficie de cada área.

Es obligatorio llegar a un acuerdo entre turismo y conservación para lograr la simbiosis que daba a conocer Gerardo Budowski y no poner en peligro los ecosistemas tropicales.

Nuestro país va a la cabeza en América Central en la promoción del turismo, en los ingresos recibidos $y$ en la cantidad de turistas que ingresan.

\section{BIBLIOGRAFÍA}

Bifani, P. Medio ambiente y desarrollo. México, Universidad de Guadalajara: 1997.

Boo, E. "Establecimiento de la capacidad de carga". Desarrollo económico compatible: ecoturismo, un manual para organizaciones conservacionistas de América Latina y el Caribe. Arlington. Virginia. The Natural Conservancy, 1995: 34-47.

Boo, E. "La explosión del ecoturismo: planificación para el manejo y desarrollo". Serie documentos técnicos 2. Sin lugar de edición: Fondo Mundial para la Naturaleza, 1992.

Borgstroon, G. The hungry planet: The modern world at the edge of famine. Nueva York: Mac Millan editions, 1965.

Boullón, R. Ecoturismo: sistemas naturales y urbanos. 2da edición. Buenos Aires, Argentina: Publicaciones de Librerías y Distribuidoras Turísticas, 2002.

Budowski, T. "Turismo a la tica". Hacia una Centroamérica verde. UICN, REDES, DEI. Departamento Ecuménico de Investigaciones. San José. Editorial DEI, 1990: 73-84.

Butler, R.W. "The concept of a tourist cycle of evolution: implications for management of resources". Canadian Geographer 24 (1). 1980: 5-12.

Carson, R. Silent spring. Nueva York: Crest edition, 1969. 
Chaverri, A y M. Cerdas. "Capacidad de carga, instrumento conceptual para el manejo de áreas protegidas". Revista Ambientico 16. 1999: 52-61.

Curry Lindahl, K. Conservar para sobrevivir: una estrategia ecológica. México: Editorial Diana, 1972.

De las Heras, M. "El ecoturismo como fórmula de desarrollo sostenible". Viñals. B. Turismo en espacios naturales y rurales. Valencia. Universidad Politécnica de Valencia, 1999: 76-99.

DeShazo, J.R y L. Monestel. "La importancia de las áreas protegidas públicas en el desarrollo del turismo en Costa Rica: Un análisis de su visita". Development discussion paper 685. Proyecto del INCAE y Harvard Institute for Internacional Development. Alajuela: Harvard University, 1999.

DeShazo, J.R y L. Monestel. "La importancia de las áreas protegidas en el desarrollo del turismo en Costa Rica: Evidencia sobre el comportamiento del gasto de los turistas nacionales y extranjeros". Development discussion paper 684 . Proyecto del INCAE y Harvard Institute for Internacional Development. Alajuela: Harvard University, 1999a.

DeShazo, J.R y L. Monestel. "Evaluación de la calidad de los lugares recreativos $y$ preferencias por lugares $y$ actividades recreacionales: La perspectiva de los turistas nacionales y extranjeros sobre las áreas protegidas públicas de Costa Rica". Development discussion paper 685. Proyecto del INCAE y Harvard Institute for Internacional Development. Alajuela: Harvard University, 1999b.

DeShazo, J.R y L. Monestel. "Costa Rica: Caracterización de los visitantes y sus opiniones para las áreas protegidas públicas y privadas". Development discussion paper 685. Proyecto del INCAE y Harvard Institute for Internacional Development. Alajuela: Harvard Univerity, 1999c.

Drumm, A y A. Moore. Desarrollo de ecoturismo. Un manual para profesionales. Arlington, Virginia, USA: Editorial Alex C. Walker Educational \& Charitable Foundation. The Nature Conservancy, 2002.

Dubos, R y W. Barbara. Una sola tierra: El cuidado y conservación de un pequeño Planeta. Barcelona: Ediciones Salvat, 1972.

Erlich, P.R. Population bomb. Nueva York: Mac Graw Hill editions, 1968.

Fennell, D.A. Ecotourism: An Introduction. New York: Routledge, 1999.

Fürst, E; M.L, Moreno; D. García y E. Zamora. Estudio: sistematización y análisis del aporte de los parques nacionales y reservas biológicas al desarrollo económico y social en Costa Rica. Heredia: Cinpe. Universidad Nacional, 2004.

Gonzales, R. "Contribution a l'étude du droit de la protection de la nature et de l'environnement au Costa Rica". [Tesis de doctorado en Derecho]. Francia: Université de Bordeaux II, 1981.

Gonzales, R. "Política, derecho y medio ambiente". Revista de Ciencias Jurídicas 54. 1985: 27-39.

Graefe, E, F. R. Kuss y J.J. Vaske. Visitor impact management. The planning framework. Washington D.C: National Parks and Conservation Association, 1990.

Gutiérrez, R. "Áreas silvestres protegidas y competitividad turística". Revista Ambientico 17. 1999: 12-14. 
Harribey, J.M. Le developpement soutenable. Paris: Editoriel Economica, 1998.

Honey, M. Ecotourism and Sustainable Development: Who Owns Paradise? Washington D.C.: Island Press, 1999.

ICT. Resumen de encuesta a turistas. San José: Instituto Costarricense de Turismo, 2005.

Kai Curry,L. Conservar para sobrevivir: Una estrategia ecológica. México: Editorial Diana, 1974.

López, A. "Turismo y desarrollo sostenible". Sistema 162-163. 2001: 185-203.

Mata, E. Aportes del programa de pequeñas donaciones al corredor biológico mesoamericano. San José: Programa de pequeñas donaciones, 1995.

Organización Mundial de Turismo. Tourism the year 2000 and beyond qualitative aspects. Madrid: OMT, 1993.

Organización Mundial de Turismo. Código Ético Mundial para el Turismo. Madrid: OMT, 2000.

Pérez Agote, A. Medio ambiente e ideología en el capitalismo avanzado. Madrid: Ediciones Encuentro, 1979.

Porras, A. "Análisis general de la legislación forestal". Revista de Ciencias Jurídicas 14. $1980^{\mathrm{a}}$ : $164-173$.
Porras, A. "Derecho ambiental de Costa Rica". Revista Judicial 20. 1981: 83-86.

Programa de Pequeñas Donaciones (PPD). "Programa de pequeñas donaciones en Costa Rica”. Informe anual. San José: PNUD, 2007.

SINAC. Políticas turísticas del SINAC. San José: Ministerio del Ambiente y Energía (MINAE), 2006.

Stankey, G; H. Cole; D.N. Lucas; M. Petersen y S.S. Frissell. The limits of acceptable change system for wilderness planning. Utah, Ogden: U.S Department of Agriculture, Forest Service, 1985.

PNUMA y UICN. Estrategia mundial para la conservación. Gland. Suiza: PNUMA-UICN, 1980.

Tamanes, R. Ecología y desarrollo: La polémica sobre los limites al crecimiento. Madrid: Alianza Editorial, 1985.

Vargas, G. "La protección de los recursos naturales en un país subdesarrollado: caso de Costa Rica". Revista de Ciencias Sociales 59. 1993: 81-94.

Wearing, N. Ecoturismo: impacto, tendencias y posibilidades. Editorial Síntesis, 2000 . 